\title{
Suitability of $\beta$-lactoglobulin micro- and nanostructures for loading and release of bioactive compounds
}

\author{
Lívia S. Simões $^{\text {a, Luís Abrunhosa }}{ }^{\text {a }}$, António A. Vicente ${ }^{\mathrm{a}}$, Oscar L. Ramos ${ }^{\mathrm{b}, *}$ \\ ${ }^{\text {a }}$ CEB - Centre of Biological Engineering, University of Minho, Campus de Gualtar, 5710-057, Braga, Portugal \\ ${ }^{\mathrm{b}} \mathrm{CBQF}$ - Centro de Biotecnologia e Química Fina, Escola Superior de Biotecnologia, Universidade Católica Portuguesa/Porto, Porto, 4169-005, Portugal
}

\section{A R T I C L E I N F O}

\section{Keywords:}

$\beta$-Lactoglobulin

Micro- and nano structures

Delivery systems

Hydrophilic compounds

Hydrophobic compounds

Food-grade

Food simulant

\begin{abstract}
A B S T R A C T
$\beta$-lactoglobulin ( $\beta$ - $\mathrm{Lg}$ ) has the ability to form three-dimensional networks when heated above denaturation temperature (ca. $76^{\circ} \mathrm{C}$ ), since it undergoes conformational changes followed by subsequent protein-protein interactions, which allows designing stable micro- and nanostructures with affinity to bind to a wide range of molecules. In this sense, $\beta$ - $\mathrm{Lg}$ micro (with particle size from 200 to $300 \mathrm{~nm}$ ) and nano (with particle size $\leq 100$ $\mathrm{nm}$ ) structures were developed as a delivery system for the controlled release of hydrophilic and hydrophobic model compounds. Several concentrations of bioactive compounds were incorporated into $\beta$ - $\mathrm{Lg}$ micro- and nanostructures and their association efficiency $(A E)$ and loading capacity $(L C)$ were determined. $\beta$-Lg structures were characterized in terms of structural properties, morphology, binding mechanisms, conformational changes and secondary structure. The impact of several conditions (e.g., pH, thermal processing, ionic strength and storage temperature) on the stability of $\beta$ - $\mathrm{Lg}$ structures was also investigated. The release profile of bioactive compounds from $\beta$ - $\mathrm{Lg}$ structures was determined in vitro using two food simulants with different hydrophobicities under different temperature conditions (at $4{ }^{\circ} \mathrm{C}$ and $25^{\circ} \mathrm{C}$ ). Data recorded showed that $\beta$ - $\mathrm{Lg}$ nanostructures had the highest $A E$ and $L C$ comparing with $\beta$ - $\mathrm{Lg}$ microstructures, for both bioactive compounds tested. $\beta$ - $\mathrm{Lg}$ microand nanostructures with or without association of bioactive compounds showed to be stable under acidic ( $\mathrm{pH} 2$ to $3)$, neutral ( $\mathrm{pH} \mathrm{6}$ ) or alkaline ( $\mathrm{pH} \mathrm{10)} \mathrm{conditions,} \mathrm{thermal} \mathrm{treatments} \mathrm{up} \mathrm{to} 70^{\circ} \mathrm{C}$ and during storage for 50 and 90 days at $25^{\circ} \mathrm{C}$ and $4{ }^{\circ} \mathrm{C}$, maintaining their particle size, PDI and surface charge $(p>0.05)$. The release kinetics of bioactive compounds from micro- and nanostructures fitted well the Linear Superimposition Model, being the relaxation the main release mechanism. Both compounds showed an initial burst effect followed by a slow release. All these findings provide new insights on which conditions the $\beta$ - $\mathrm{Lg}$ micro- and nanostructures are more stable, and therefore more suitable to act as potential delivery systems for hydrophilic and hydrophobic bioactive compounds.
\end{abstract}

\section{Introduction}

The emerging demand for safer, nutritious and high-quality functional foods as a way to address specific human health requirements has gained recently the attention from food industry players and scientific community for developing new sustainable ways to encapsulate, protect and deliver bioactive compounds in food products (Devi, Sarmah, Khatun, \& Maji, 2017; Sedaghat Doost, Muhammad, Stevens, Dewettinck, \& Van der Meeren, 2018).

$\beta$-lactoglobulin ( $\beta$ - Lg), the main protein fraction of whey proteins, is an interesting matrix for designing delivery systems for controlled release of bioactive compounds, due to its bio-based nature, Generally
Recognized As Safe (GRAS) designation, high nutritional value, biological and functional (e.g., emulsification) properties, as well as, to its gelation and high binding capacity (Madalena et al., 2016). The conformational state of native $\beta$ - $\mathrm{Lg}$ becomes unfolded when induced by thermal heating, thus resulting in the exposure of initially buried hydrophobic aminoacid residues with subsequent self-aggregation of protein molecules through physical (electrostatic and hydrophobic) and chemical (disulphide) interactions (Delahaije, Wierenga, Giuseppin, \& Gruppen, 2015). $\beta$-Lg structural characteristics abovementioned allows it to perform well as delivery system for various hydrophilic and hydrophobic bioactive compounds (Aprodu, Ursache, Turturica, Râpeanu, \& Stanciuc, 2017).

\footnotetext{
* Corresponding author.

E-mail address: os.silva.ramos@gmail.com (O.L. Ramos).
} 
Even though previous researches demonstrated that $\beta$ - Lg has affinity to bind to a wide range of molecules with distinct physiochemical properties (e.g., solubility in water, molecular weight, and structure), its ability to act as delivery system is still limited and there are current challenges related with binding to bioactive compounds that need to be, firstly, well understood, and then overcome. For instance, Berino et al. (2019) investigated the interaction between $\beta$ - $\mathrm{Lg}$ with vitamin $\mathrm{D}_{3}$ (at several concentrations) and the stability of the complex formed to protect vitamin $\mathrm{D}_{3}$ from degradation by light, oxygen and pressure. The authors found limitations in the binding of vitamin $\mathrm{D}_{3}$ to the hydrophobic sites in the calyx and to the hydrophobic surface patches of $\beta$ - $\mathrm{Lg}$ with conformational changes recorded in the protein secondary structure. In another study, Guo, Harris, Kaur, Pastrana, and Jauregi (2017) aimed at masking caffeine's bitter taste and unpleasant aftertaste by using $\beta$-Lg nanoparticles as delivery systems. The authors obtained low encapsulation efficiencies (i.e., $13.5 \%$ ). In fact, the delivery systems should display high encapsulation efficiencies of bioactive compounds and protect them against degradation during production and over storage periods. However, information regarding the best conditions to design and process $\beta$ - $\mathrm{Lg}$ delivery systems, about their performance as encapsulating agents, stability in several environmental conditions (e.g., $\mathrm{pH}$ values, ionic strength, temperature) and over time, ability to bind bioactive compounds and behaviour in food matrices is very scarce or inexistent. A few studies are available regarding the use of other proteins as encapsulating agents for bioactive compounds with emphasis to one conducted by Bourbon, Cerqueira, et al. (2016) and Bourbon, Pinheiro, et al. (2016). These authors developed lactoferrin-glycomacropeptide nanohydrogels by thermal gelation to encapsulate curcumin (as model lipophilic compound) and caffeine (as model hydrophilic compound). This study showed that such nanohydrogels successfully bound both bioactive compounds, enhanced their antimicrobial activity and promoted their controlled release.

Taking into account the limited information available regarding the use of proteins as bio-based delivery systems, and in particular of $\beta-\mathrm{Lg}$, it is considered of utmost importance to understand how different sizes of $\beta$ - $\mathrm{Lg}$ structures, below and above $100 \mathrm{~nm}$, may affect their physicochemical properties. According to Recommendation 2011/696/EU of the European Commission of 18 October 2011 (Commission, 2011a), and to recent literature reviews (Jafari, 2017; Mcclements, 2017; Singh, 2016) a nanomaterial means "A natural, incidental or manufactured material containing particles, in an unbound state or as an aggregate or as an agglomerate and where, for $50 \%$ or more of the particles in the number size distribution, one or more external dimensions is in the size range $1 \mathrm{~nm}-100 \mathrm{~nm}$ ". This definition aims to inform the consumers and proceed as a guideline to different regulatory sectors. Therefore, in this study, $\beta$ - $\mathrm{Lg}$ structures at nano- (with diameters $\leq 100 \mathrm{~nm}$ ) and at micro(with diameters between 200 and $300 \mathrm{~nm}$ ) scales were used to understand how its size may impact the encapsulation, protection and controlled release of bioactive compounds. Due to reduced size, the micro-, and even more, the nanostructures may be able to improve the solubility, bioavailability, and protect the bioactive compounds from degradation when compared with macrostructures formed from the same protein (Monteiro et al., 2016; Simões, Araújo, Vicente, \& Ramos, 2020). This behaviour can be resulted from a high surface/volume ratio, but also from different effects of physical and chemical interactions imparting by $\beta$ - $\mathrm{Lg}$ nano- (with diameters $\leq 100 \mathrm{~nm}$ ) and micro- (with diameters between 200 and $300 \mathrm{~nm}$ ) structures, which may have a significant influence on their performance as potential delivery systems (Cerqueira et al., 2014).

In this context, $\beta$ - $\mathrm{Lg}$ nano- (with diameters $\leq 100 \mathrm{~nm}$ ) and micro(with diameters between 200 and $300 \mathrm{~nm}$ ) structures were proposed here as potential delivery systems to encapsulate, protect and controlled release of bioactive compounds (i.e., riboflavin and quercetin) with different water solubilities. Riboflavin is a vitamin essential to human growth (Beztsinna, Solé, Taib, \& Bestel, 2016), however this compound cannot be naturally synthetized by the human body, thus must be obtained from external sources (Gironés-Vilaplana, Villaño, Marhuenda, Moreno, \& García-Viguera, 2017). Nonetheless, its use in food products is still limited by several issues such as its high degradability when exposed to light and low solubility in water (Ashoori \& Saedisomeolia, 2014). For all these reasons riboflavin was studied as hydrophilic model compound. Quercetin attracted the interest of the scientific community due to its anticancer, antioxidant and antiviral activities (Haghi, Azimi, \& Rahimi, 2017). However, its use in food products is still limited due to its hydrophobic nature (i.e., poor aqueous solubility), low oral bioavailability (i.e., it is highly degraded through the gastrointestinal tract), and stability (Aditya et al., 2014). Therefore, quercetin was investigated as hydrophobic model compound. Hence, this research aims at deepening the understanding of the binding mechanisms of $\beta-\mathrm{Lg}$ micro- and nanostructures to riboflavin (as model hydrophilic compound) and quercetin (as model hydrophobic compound) and assess their potential as encapsulating agents. Also, the impact of various environmental conditions on the physicochemical stability of loaded $\beta$-Lg micro- and nanostructures, and the release profile of such model compounds from $\beta$-Lg micro- and nanostructures when they are added into food simulants, will be assessed.

\section{Materials and methods}

\subsection{Feedstocks and chemicals}

The following chemicals were purchased from Sigma-Aldrich (St. Louis, MO, USA): quercetin ( $\geq 95 \%$, HPLC), riboflavin ( $\geq 98 \%$ ), sodium azide, ANS (8-Anilino-1-napththalenesulfonic), and sodium phosphate tribasic dodecahydrate $98 \%$. Whey Protein Isolate (WPI) powder (Lacprodan DI-9212), kindly supplied by Arla Foods Ingredients (Viby, Denmark), has in a total protein content of $91 \%$ (in dry weight), moisture content of ca. $6 \%$ and vestiges of lactose (max. $0.5 \%$ ) and fat (max. $0.2 \%$ ), according to the information provided by the supplier. Sodium hydroxide and phosphoric acid were obtained from Merck (Merck KGaA, Darmstadt, Germany). Hydrochloric acid and monosodium phosphate were purchased from Panreac (Barcelona, Spain), whereas sodium phosphate dibasic, acetonitrile (HPLC grade) and methanol were obtained from Chem-Lab (Zedelgem, Belgium). Dimethyl sulfoxide was obtained from Fisher Scientific, while ethanol was purchased from JMGS (Portugal). All other chemicals used in this study were reagents of analytical grade.

\subsection{Development of $\beta-L g$ micro- and nanostructures}

$\beta$-Lg micro- and nanostructures were prepared according to the procedure previously optimized (Simões et al., 2020). For this purpose, $\beta$-Lg powder at 5 and $15 \mathrm{mg} \mathrm{mL}^{-1}$ was used to develop nano- and microstructures, respectively, being dissolved in sodium phosphate buffer at $\mathrm{pH} 6$ containing $0.02 \%$ of sodium azide (used as preservative to avoid microbial growth). The $\mathrm{pH}$ was adjusted with $0.5 \mathrm{~mol} \mathrm{~L}^{-1}$ of $\mathrm{H}_{3} \mathrm{PO}_{4}$ and/or $1 \mathrm{~mol} \mathrm{~L}^{-1}$ of $\mathrm{NaOH}$, as necessary. Then, solutions were stirred continuously during $120 \mathrm{~min}$ at $400 \mathrm{rpm}$ at room temperature (ca. 25 $\left.{ }^{\circ} \mathrm{C}\right)$. The $\beta$ - $\mathrm{Lg}$ solutions were kept overnight at a temperature of $4{ }^{\circ} \mathrm{C}$ to ensure full protein rehydration. Afterwards, the samples were filtered through a $0.2 \mu \mathrm{m}$ cellulose acetate membrane syringe filter (VWR International, USA) to remove any protein aggregates or impurities. Subsequently, $\beta$ - $\mathrm{Lg}$ solutions were placed into cylindrical screw-capped glass tubes ( $100 \mathrm{~mm}$ total length and diameter of $20 \mathrm{~mm}$ ) and submitted to thermal treatment at $80{ }^{\circ} \mathrm{C}$ for $15 \mathrm{~min}$ (conditions previously optimized) then cooled in ice for $10 \mathrm{~min}$.

\subsection{Association efficiency and loading capacity}

After $\beta$-Lg solutions thermal treatment, a given volume of each bioactive compound stock solution was added to the resulting $\beta$ - $\mathrm{Lg}$ solutions, and then were cooled in ice for $10 \mathrm{~min}$ to form $\beta$ - $\mathrm{Lg}$ micro- and 
nanostructures.

\subsubsection{Riboflavin - hydrophilic bioactive model compound}

Riboflavin, as a hydrophilic bioactive model compound, was dissolved in $0.1 \mathrm{~mol} \mathrm{~L}^{-1} \mathrm{Na}_{3} \mathrm{PO}_{4}$, being the resulting solutions protected from light with aluminium foil (Zhang et al., 2016) to obtain $\beta$-Lg solutions with final concentrations of riboflavin ranging from 0.007 to $0.105 \mathrm{mg} \mathrm{mL}^{-1}$.

In order to separate the free riboflavin in supernatant, $0.5 \mathrm{~mL}$ of $\beta$ - $\mathrm{Lg} /$ riboflavin micro- and nanostructure solutions were placed into Amicon ${ }^{\circledR}$ Ultra - $0.5 \mathrm{~mL}$ centrifugal filter units with molecular weight cut-off $3 \mathrm{kDa}$ (Merck Millipore, Ireland) and centrifuged (Model $5415 \mathrm{R}$, Eppendorf) at $16,000 \mathrm{~g}$ during $20 \mathrm{~min}$ at $4{ }^{\circ} \mathrm{C}$. The filtrate with unbound riboflavin was determined spectrophotometrically at $437 \mathrm{~nm}$ (Azevedo, Bourbon, Vicente, \& Cerqueira, 2014) using the calibration curve $y=$ $7.9841 x+0.056$ with $R^{2}=0.99$ (being $y$ and $x$ the absorbance and riboflavin concentration, respectively). These results were used to calculate the association efficiency $(A E)$ according to Equation (1). The concentrate with the $\beta-\mathrm{Lg} /$ riboflavin micro- and nanostructure retained in Amicon ${ }^{\circledR}$ was dried at $55{ }^{\circ} \mathrm{C}$ during $24 \mathrm{~h}$ in a ventilated oven and the loading capacity $(L C)$ was determined by mass difference according to Equation (2).

$A E(\%)=\frac{C_{\text {Bioactive compound total }}-C_{\text {Bioactive compound free }}}{C_{\text {Bioactive compound total }}} \times 100$

$L C(\%)=\frac{C_{\text {Bioactive compound total }}-C_{\text {Bioactive compound free }}}{W_{\text {structure }}} \times 100$

where, $C_{\text {Bioactive compound total }}$ is the concentration of bioactive compound in solution; $C_{\text {Bioactive compound free }}$ is the concentration of free bioactive compound separated from $\beta$ - $\mathrm{Lg}$ structures; and $W_{\text {structure }}$ is the $\beta$ - $\mathrm{Lg}$ structure weight.

\subsubsection{Quercetin - hydrophobic bioactive model compound}

The addition of quercetin to an ethanol solution (used as solvent) was limited due to the protein sensitivity to ethanol (Pace et al., 2004). Distinct quercetin concentrations were previously dissolved in ethanol in order to achieve quercetin concentrations ranging from 0.01 to 0.08 $\mathrm{mg} \mathrm{mL}^{-1}$. $\beta$-Lg/quercetin micro- and nanostructures $(2 \mathrm{~mL})$ were placed into tube samples and subsequently centrifuged (Model 5415 R, Eppendorf) at $14,000 \mathrm{~g}$ for $10 \mathrm{~min}$ at $4{ }^{\circ} \mathrm{C}$, to separate the unbound quercetin (Madalena et al., 2016). The free quercetin in the supernatant was evaluated by high-performance liquid chromatography (HPLC) with fluorescence detection. The HPLC system used consisted of a Varian Prostar 210 pump, a Varian Prostar 410 autosampler, and a Jasco FP-920 detector. The column was a C18 reversed-phase YMC-Pack ODS ( $4.6 \times 250 \mathrm{~mm}$ i.d; $5 \mu \mathrm{m}$ particle size). The mobile phase was composed of acetonitrile and distilled water $(40: 60, \mathrm{v} / \mathrm{v})$, and was pumped at a flow rate of $1.0 \mathrm{~mL} \mathrm{~min}^{-1}$. The wavelengths used for quercetin detection were excitation $=355 \mathrm{~nm}$ and emission $=525 \mathrm{~nm}$ (Komori, Inoue, Fujita, Kasajima, \& Horii, 2007). The quantification was performed using a calibration curve prepared with standards at concentrations between 0.01 and $0.1 \mathrm{mg} \mathrm{mL}^{-1}$. These results were used to assess the $A E$ by Equation (1). The $\beta$ - $\mathrm{Lg}$ /quercetin micro- and nanostructures were dried at $55{ }^{\circ} \mathrm{C}$ during $24 \mathrm{~h}$ in a ventilated oven and the $L C$ was determined using Equation (2).

\subsection{Stability under various environmental conditions}

The stability of $\beta$ - $\mathrm{Lg}$ micro- and nanostructures in the absence and presence of bioactive model compounds under various environmental conditions (i.e., $\mathrm{pH}$, ionic strength, thermal processing and storage temperature) was evaluated in terms of their particle size, polydispersity index (PDI) and surface charge (S) by dynamic light scattering (DLS) instrument.

\subsection{1. $p H$ stability}

The effect of $\mathrm{pH}$ was assessed by ranging $\mathrm{pH}$ between 2 and 10 using $0.1 \mathrm{~mol} \mathrm{~L}^{-1} \mathrm{NaOH}$ and/or $0.1 \mathrm{~mol} \mathrm{~L}^{-1} \mathrm{H}_{3} \mathrm{PO}_{4}$, as necessary.

\subsubsection{Ionic strength stability}

The influence of ionic strength was evaluated on $\beta$-Lg micro- and nanostructures in the absence and presence of bioactive model compounds by adding distinct $\mathrm{NaCl}$ concentrations $\left(0-200 \mathrm{mmol} \mathrm{L}^{-1}\right)$ (Bourbon et al., 2015; Tokle, Mao, \& McClements, 2013).

\subsubsection{Temperature stability}

Thermal stability was assessed by DLS, using the temperature range from 20 to $80{ }^{\circ} \mathrm{C}$, with increments of $5{ }^{\circ} \mathrm{C}$, with $60 \mathrm{~s}$ of equilibration before each measurement (Martins et al., 2016).

\subsubsection{Storage temperature stability}

Samples were stored at temperatures of $4{ }^{\circ} \mathrm{C}$ (to simulate refrigeration conditions) and $25{ }^{\circ} \mathrm{C}$ (to simulate room temperature conditions) over 90 days, and at an appropriate interval of time, particle size, PDI and surface charge (S) were measured (Monteiro et al., 2016).

\subsection{Physicochemical characterization}

\subsubsection{Particle size, polydispersity index and surface charge}

Freshly prepared $\beta$-Lg structures were used to measure particle size, polydispersity index (PDI) and surface charge (S) using a DLS instrument (Zetasizer Nano ZS, Malvern Instruments, UK) equipped with $\mathrm{He}-\mathrm{Ne}$ laser at a wavelength of $633 \mathrm{~nm}$. $\beta-\mathrm{Lg}$ samples $(1.5 \mathrm{~mL})$ were poured into disposable sizing cuvettes with a path length of $10 \mathrm{~mm}$ for particle size and PDI analyses, which carried out with detection angle of $173^{\circ}$ (Bourbon et al., 2016). Surface charge (S) of samples was performed by $\zeta$ - potential measurements into a folded capillary cell. All samples were equilibrated at $25{ }^{\circ} \mathrm{C}$ before measurements were performed. The results are given as mean \pm standard deviation of nine measures obtained.

\subsubsection{Extrinsic fluorescence}

The extrinsic fluorescence was carried out by fluorescence spectroscopy (Jasco FP6200, Tokyo, Japan) using 8-anilinonaphtalene-1-sulfonic acid ammonium salt (ANS) (Sigma-Aldrich, St. Louis, EUA) to assess the hydrophobic sites of $\beta$ - $\mathrm{Lg}$ micro- and nanostructures with/ without bioactive model compound associated.

For this propose, an ANS stock solution at $1.36 \mathrm{mmol} \mathrm{L}^{-1}$ was prepared in methanol in the absence of light, before analyses were performed. Subsequently, $20 \mu \mathrm{L}$ of ANS solution were added into $\beta$-Lg samples ( $4 \mathrm{~mL}$ ), in appropriated dilution, and incubated at $25^{\circ} \mathrm{C}$ during 10 min (Wang, Zhong, \& Hu, 2013). Fluorescence measurements of resulting solutions were performed using a $10 \mathrm{~mm}$ path length quartz cuvette with excitation wavelength at $370 \mathrm{~nm}$, and emission spectra were recorded from 400 to $600 \mathrm{~nm}$ at room temperature (ca. $25{ }^{\circ} \mathrm{C}$ ). Data results of extrinsic fluorescence peaks were given in arbitrary units and analysed by ORIGIN 9.0 program (Multiple Peak Fit).

\subsubsection{Circular dichroism spectra}

Circular dichroism (CD) spectra were recorded using a Jasco J-1500 spectropolarimeter (Jasco International Co, Japan) to evaluate the $\beta-\mathrm{Lg}$ secondary structure content and the effect of binding of bioactive model compounds. $\beta$ - Lg samples, in appropriate dilution, were poured into a quartz cell with a path length of $1.0 \mathrm{~mm}$ (Hellma Analytics, Germany). Far-UV spectra ranging from 190 to $260 \mathrm{~nm}$ wavelength was performed under nitrogen atmosphere with data pitch of $1.0 \mathrm{~nm}$, accumulation of 3 scans at a scan speed of $50 \mathrm{~nm} \mathrm{~min}{ }^{-1}$ at $25{ }^{\circ} \mathrm{C}$ (Bourbon et al., 2016). The $\mathrm{CD}$ spectra were presented as the average of three measurements.

\subsubsection{Fourier - transform infrared spectroscopy}

The binding of bioactive model compounds to $\beta$ - $\mathrm{Lg}$ micro- and nanostructures was evaluated by Fourier-transform infrared (FTIR) 
spectra (model ABB FTLA2000, Canada), according to the procedure adopted by (Martins et al., 2016) with a few modifications. Samples (2 $\mathrm{mg}$ ) were prior lyophilized, and then compressed into thin potassium bromide $(\mathrm{KBr})(200 \mathrm{mg})$ pellets and finally analysed in a wavenumber range of 4000 to $500 \mathrm{~cm}^{-1}$. Each spectrum was performed by averaging 16 scans with a spectral resolution of $8 \mathrm{~cm}^{-1}$. Data analysis was performed using ORIGIN 9 software.

\subsection{Transmission electronic microscopy}

Transmission electron microscopy (TEM) imaging of $\beta$ - $\mathrm{Lg}$ micro- and nanostructures associated with bioactive model compounds was performed by negative staining method using a Zeiss EM 902A (Thornwood, N.Y., USA) microscope at accelerating voltages of 50 and $80 \mathrm{kV}$. A drop of sample dispersion was deposited onto a carbon support film mounted on a TEM copper grid (Quantifoil, Germany) and excess of the solution was removed after 2 min using a filter paper and the grid let for air drying. The samples were then negatively stained with uranyl acetate $(2 \% \mathrm{w} / \mathrm{w})$ (Merck, Germany) during $15 \mathrm{~s}$. The grid was finally air dried at room temperature before introducing it in the electron microscope. This methodology was performed according to procedures usually adopted by our research group (Bourbon et al., 2015; Monteiro et al., 2016; Pinheiro et al., 2015).

\subsection{In vitro release profile}

The in vitro release profiles of bioactive model compounds were evaluated by dialysis over $72 \mathrm{~h}$ (Azevedo et al., 2014; Bourbon et al., 2016). These experiments used two food simulant solutions, composed by 10 and $50 \%$ of ethanol to simulate hydrophilic and hydrophobic food matrices, respectively, according with the Commission Regulation (EU) No 10/2011 of 14 January 2011 (Commission, 2011b), and were conducted at $4{ }^{\circ} \mathrm{C}$ (to mimic refrigerated temperatures) and at $25{ }^{\circ} \mathrm{C}$ (to mimic room temperature).

Samples $(5 \mathrm{~mL})$ were placed inside of a dialysis membrane with cutoff $10 \mathrm{kDa}$ (Spectra/Por, Spectrum Laboratories, USA) and then placed into a reactor with $50 \mathrm{~mL}$ of food simulant solutions under continuous magnetic stirring at $200 \mathrm{rpm}$. At appropriate time intervals, $0.3 \mathrm{~mL}$ of supernatant was taken and replaced by the same quantity of fresh food simulant solution to maintain the volume constant. The quantity of riboflavin and quercetin released from $\beta$ - $\mathrm{Lg}$ micro- and nanostructures were evaluated by spectrophotometry for riboflavin and by HPLC for quercetin. These experiments were performed at least in triplicate.

\subsubsection{In vitro release kinetics}

The release mechanisms of bioactive model compounds from $\beta$ - $\mathrm{Lg}$ micro- and nanostructures were assessed by the kinetic model proposed by Berens and Hopfenberg (1978), which considers both Fickian and Case II transport effects as evidenced in Equation (3):

$M_{t}=M_{t, F}+M_{t, R}$

where, $M_{t}$ is the total mass released from polymeric $\beta$-Lg micro- and nanostructures at time $t ; M_{t, F}$ and $M_{t, R}$ are the contributions of the Fickian and biopolymer relaxation effects, respectively.

The Fickian transport is described by Equation (4), as follows:

$M_{t, F}=M_{\infty, F}\left[1-\frac{6}{\pi^{2}} \sum_{n=1}^{\infty} \frac{1}{n^{2}} \exp \left(-n^{2} k_{F} t\right)\right]$

where, $M_{\infty, F}$ is the bioactive compound released at equilibrium and $k_{F}$ is the Fickian diffusion rate constant. Eq. (4) can be simplified by applying the first term of the Taylor series (Pinheiro, Bourbon, Quintas, Coimbra, \& Vicente, 2012), as presented in Equation (5):
$M_{t, F}=M_{F}\left[1-\frac{6}{\pi^{2}} \exp \left(k_{F} t\right)\right]$

Regarding biopolymer relaxation, it is driven by biopolymer swelling capacity and then associated to the dissipation of stress induced by the penetrant entrance. This behaviour can be characterized as a distribution of relaxation times, each assuming a first order-type kinetic equation (Berens \& Hopfenberg, 1978), as follows Equation (6):

$M_{t, R}=\sum_{i} M_{\infty, R i}\left[1-\exp \left(-k_{R i} t\right)\right]$

where, $M_{\infty, R i}$ is the contribution of the relaxation processes for bioactive compound release and $k_{R i}$ is the relaxation ith rate constant. Commonly, only one main biopolymer relaxation influences the relaxation transport (i.e. $i=1$ ) (Bourbon et al., 2016).

Thereby, the linear superimposition model (LSM) for bioactive model compounds released from $\beta$ - $\mathrm{Lg}$ micro- and nanostructures can be described by Equation (7):

$\frac{M_{t}}{M_{\infty}}=X\left[1-\frac{6}{\pi^{2}} \exp \left(-k_{F} t\right)\right]+(1-X)\left[1-\exp \left(-k_{R} t\right)\right]$

where $X$ is the fraction of bioactive compounds released by Fickian transport.

Experimental data were fitted with Eq. (7) (LSM) to evaluate the transport mechanism involved in riboflavin and quercetin release from $\beta$-Lg micro- and nanostructures at hydrophilic and hydrophobic food simulants at 4 and $25{ }^{\circ} \mathrm{C}$.

\subsection{Statistical analyses}

The whole experiment was run at least in triplicate and was expressed as average \pm standard deviation. The results were statistically analysed with one-way ANOVA followed by post hoc Tukey's tests using $p \leq 0.05$ as the level of significance.

Equations (4) and (7) were fitted to experimental data using a nonlinear regression. The least square function minimization was done by the Leveberg-Marquardt algorithm. The quality of regression curves was assessed by the determination coefficient $\left(R^{2}\right)$ and the squared root mean square error (RMSE). All statistical analyses were performed using the package of Statistica software version 10.0.228.8 (StatSoft Inc, USA.).

\section{Results and discussion}

\subsection{Bioactive model compounds association}

According to the available literature, $\beta$ - $\mathrm{Lg}$ has the capability to associate both hydrophilic and hydrophobic bioactive compounds (Aprodu et al., 2017; Xu et al., 2019; Zagury, Kazir, \& Livney, 2019). The different physicochemical properties of bioactive compounds (e.g., molecular weight, water solubility and chemical structure) can affect the behaviour of $\beta-\mathrm{Lg}$ structures. Therefore, a range of concentrations of each model bioactive compound associated to $\beta$ - $\mathrm{Lg}$ micro- and nanostructures were investigated in terms of association efficiency $(A E)$, loading capacity $(L C)$, particle size, polydispersity (PDI) and surface charge (S). $A E$ provides information about the bioactive compound fraction successfully entrapped within structures (Mirpoor, Hosseini, \& Nekoei, 2017), whereas LC is related to the maximum amount of bioactive model compound that can be loaded into a $\beta$ - Lg structure (Zou et al., 2016).

Table 1 shows the results obtained for $\beta$ - Lg micro- and nanostructures associated to riboflavin, used as hydrophilic model compound.

The $A E$ (Table 1) of $\beta$ - $\mathrm{Lg} /$ riboflavin microstructures ranged between 31.9 and $64.4 \%(p \leq 0.05)$, as riboflavin concentration increased. In 
Table 1

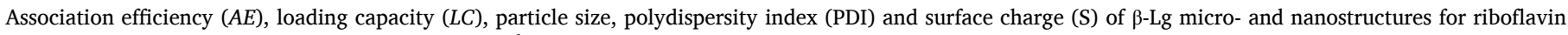
concentrations (RC) ranging from 0 to $0.105 \mathrm{mg} \mathrm{mL}^{-1}$.

\begin{tabular}{|c|c|c|c|c|c|c|}
\hline$\beta$-Lg structure & $\mathrm{RC}\left(\mathrm{mg} \mathrm{mL}^{-1}\right)$ & $A E(\%)$ & $L C(\%)$ & Particle size (nm) & PDI & $\mathrm{S}(\mathrm{mV})$ \\
\hline \multirow[t]{6}{*}{ Micro } & 0 & - & - & $246.0 \pm 10.5^{\mathrm{a}}$ & $0.20 \pm 0.01^{\mathrm{a}}$ & $-20.1 \pm 2.1^{\mathrm{a}}$ \\
\hline & 0.007 & $31.9 \pm 1.2^{\mathrm{aA}}$ & $0.04 \pm 0.01^{\mathrm{aA}}$ & $288.4 \pm 10.5^{\mathrm{b}}$ & $0.24 \pm 0.01^{\mathrm{b}}$ & $-22.5 \pm 1.2^{\mathrm{a}}$ \\
\hline & 0.0105 & $40.0 \pm 1.6^{\mathrm{bA}}$ & $0.07 \pm 0.01^{\mathrm{aA}}$ & $275.6 \pm 7.5^{\mathrm{ab}}$ & $0.21 \pm 0.01^{\mathrm{ac}}$ & $-20.4 \pm 1.4^{\mathrm{a}}$ \\
\hline & 0.014 & $43.9 \pm 0.6^{\mathrm{cA}}$ & $0.09 \pm 0.01^{\mathrm{aA}}$ & $274.0 \pm 9.0^{\mathrm{ab}}$ & $0.23 \pm 0.01^{b c}$ & $-20.6 \pm 1.1^{\mathrm{a}}$ \\
\hline & 0.049 & $58.7 \pm 1.3^{\mathrm{dB}}$ & $0.44 \pm 0.05^{\mathrm{bA}}$ & $306.5 \pm 27.9^{b}$ & $0.26 \pm 0.01^{\mathrm{d}}$ & $-21.6 \pm 1.6^{\mathrm{a}}$ \\
\hline & 0.105 & $64.4 \pm 0.8^{\mathrm{eB}}$ & $1.13 \pm 0.03^{\mathrm{cA}}$ & $281.0 \pm 26.7^{\mathrm{b}}$ & $0.23 \pm 0.01^{b c}$ & $-21.1 \pm 1.0^{\mathrm{a}}$ \\
\hline \multirow[t]{6}{*}{ Nano } & 0 & - & - & $88.6 \pm 4.2^{\mathrm{a}}$ & $0.22 \pm 0.01^{\mathrm{a}}$ & $-18.9 \pm 1.2^{\mathrm{abc}}$ \\
\hline & 0.007 & $44.5 \pm 3.6^{\mathrm{aB}}$ & $0.09 \pm 0.01^{\mathrm{aB}}$ & $83.9 \pm 3.6^{\mathrm{a}}$ & $0.23 \pm 0.01^{\mathrm{a}}$ & $-16.5 \pm 0.3^{\mathrm{a}}$ \\
\hline & 0.0105 & $54.9 \pm 1.6^{\mathrm{bB}}$ & $0.15 \pm 0.02^{\mathrm{aB}}$ & $86.4 \pm 6.5^{\mathrm{a}}$ & $0.26 \pm 0.01^{\mathrm{b}}$ & $-17.7 \pm 1.1^{\mathrm{abc}}$ \\
\hline & 0.014 & $67.9 \pm 1.4^{\mathrm{cdB}}$ & $0.24 \pm 0.01^{\mathrm{aB}}$ & $88.5 \pm 8.1^{\mathrm{a}}$ & $0.25 \pm 0.01^{b}$ & $-17.4 \pm 1.7^{\mathrm{ab}}$ \\
\hline & 0.049 & $60.2 \pm 4.7^{\mathrm{dB}}$ & $0.89 \pm 0.14^{\mathrm{bB}}$ & $91.1 \pm 5.5^{\mathrm{a}}$ & $0.22 \pm 0.01^{\mathrm{a}}$ & $-19.5 \pm 1.0^{\mathrm{bc}}$ \\
\hline & 0.105 & $64.4 \pm 0.9^{\mathrm{cdB}}$ & $1.80 \pm 0.16^{\mathrm{cB}}$ & $87.8 \pm 1.9^{\mathrm{a}}$ & $0.22 \pm 0.01^{\mathrm{a}}$ & $-21.1 \pm 1.8^{\mathrm{c}}$ \\
\hline
\end{tabular}

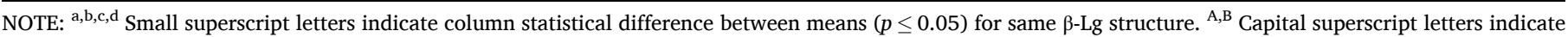
column statistical difference between means $(p \leq 0.05)$ for different $\beta$-Lg structures.

turns, $\beta-\mathrm{Lg} /$ riboflavin nanostructures achieved the highest $A E$ of $67.9 \%$ at $0.014 \mathrm{mg} \mathrm{mL}^{-1}$ of riboflavin $(p>0.05)$. Above this riboflavin concentration, the $A E$ did not significantly change, thus suggesting that this is the maximum concentration that such $\beta$ - Lg nanostructures can associate. In a study conducted by Guo et al. (2017), it was shown that $\beta$-Lg nanoparticles were able to bind caffeine (used as hydrophilic bioactive compounds) with an $A E$ of $13.54 \pm 3.3 \%$ for a caffeine: $\beta$ - $L g$ ratio of 50:1. In our work, $\beta$ - $\mathrm{Lg} /$ nanostructures demonstrated a $A E 4.8$ times higher for a lower riboflavin: $\beta$ - $L g$ ratio (i.e., 21:1).

On the other hand, the $L C$ increased as riboflavin concentration increases, independently of $\beta$ - $L$ g structure scale, as depicted in Table 1. LC values achieved a maximum of $1.80 \pm 0.16 \%$ and $1.13 \pm 0.03 \%$ $(p \leq 0.05)$, for nano- and microstructures, respectively. This result is somehow expected, taking into consideration the higher surface area-tovolume ratio of nanoscale materials, which can bind higher concentrations of bioactive compounds (Jafari \& McClements, 2017). Azevedo et al. (2014) reported a similar behaviour for alginate/chitosan nanoparticles, which presented $A E$ of $55.9 \pm 5.6 \%$ and a $L C$ of $2.2 \pm 0.6 \%$ for riboflavin. In another study, Shpigelman, Cohen, and Livney (2012) developed $\beta$ - $\mathrm{Lg}$ nanosystems by thermal gelation at $70{ }^{\circ} \mathrm{C}$ for $20 \mathrm{~min}$ at pH 6.8 for encapsulation of (-)-epigallocatechin-3-gallate. These authors obtained nanosystems with particles sizes lower than $50 \mathrm{~nm}$, which displayed similar $A E$ (i.e., $58.5 \pm 2.1 \%)$ and $L C(1.16 \pm 0.04 \%)$ values.

In terms of particle sizes, it is possible to see (Table 1) that $\beta-\mathrm{Lg} /$ riboflavin nanostructures remained with monomodal particle size distribution ( $p>0.05)$, thus suggesting that association of riboflavin did not significantly affect $(p>0.05)$ its overall size. On the other hand, for $\beta$ - $\mathrm{Lg} /$ riboflavin microstructures it was observed a statistically significant increase of particles' diameter $(p \leq 0.05)$ as the concentration of riboflavin increased. This behaviour may be attributed to structural rearrangement of $\beta$ - $\mathrm{Lg}$ microstructures after riboflavin association. For both $\beta$-Lg micro- and nanostructures the PDI values were relatively low (i.e., below 0.26 ), suggesting a relatively homogenous $\beta$ - Lg structure and a narrow size distribution. Regarding surface charge (S), $\beta$ - $\mathrm{Lg} /$ riboflavin micro- and nanostructures displayed relatively constant values ranging from -16.5 to $-20.1 \mathrm{mV}$, thus indicating that electrostatic repulsion forces among the particles are enough to prevent aggregation.

The effect of quercetin concentration on $\beta-\mathrm{Lg}$ micro- and nanostructures was also investigated, and the results are presented in Table 2.

Concerning the results presented in Table 2 , the $A E$ of $\beta$ - $\mathrm{Lg}$ /quercetin micro- and nanostructures ranged from $84.5 \pm 3.2 \%$ to $98.0 \pm 0.9 \%$. These $A E$ values agree with those found in the literature. For example, Mirpoor et al. (2017) reported that nanostructures prepared with $\beta$ - $\mathrm{Lg}$ and sodium alginate showed $A E$ higher than $93 \%$; Li et al. (2019) showed that zein particles with soluble soybean polysaccharide coating displayed $A E$ of $82.5 \%$; and Wijaya, Harfieyanto, Dewettinck, Patel, and Van der Meeren (2019) showed that whey protein isolate-low methoxyl pectin electrostatic complexes had values of $A E$ of $97 \%$. However, these structures required both protein and polysaccharide polymers associated to form a stable delivery system.

The $A E$ obtained in this study for quercetin is slightly higher than that obtained for riboflavin (Tables 1 and 2). This difference can be due to the hydrophobic/hydrophilic amino acids located in a balanced way along the $\beta$-Lg polypeptide chains (Ramos et al., 2014). During thermal gelation (thermal treatment at $80{ }^{\circ} \mathrm{C}$ for $15 \mathrm{~min}$ ), the hydrophobic binding sites initially buried inside the $\beta$-Lg structure, become exposed and available to bind, thus enhancing the potential to bind to hydrophobic bioactive compounds through hydrophobic interactions. On the

Table 2

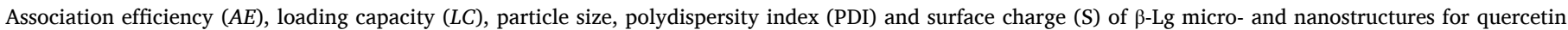
concentrations (QC) ranging from 0 to $0.08 \mathrm{mg} \mathrm{mL}^{-1}$.

\begin{tabular}{|c|c|c|c|c|c|c|}
\hline$\beta$-Lg structure & $\mathrm{QC}\left(\mathrm{mg} \mathrm{mL}^{-1}\right)$ & $A E(\%)$ & $L C(\%)$ & Particle size (nm) & PDI & $\mathrm{S}(\mathrm{mV})$ \\
\hline \multirow[t]{6}{*}{ Micro } & 0 & - & - & $243.3 \pm 2.9^{\mathrm{a}}$ & $0.19 \pm 0.01^{\mathrm{a}}$ & $-20.0 \pm 1.1^{\mathrm{a}}$ \\
\hline & 0.01 & ND & ND & $264.4 \pm 16.2^{\mathrm{b}}$ & $0.16 \pm 0.01^{\mathrm{b}}$ & $-15.9 \pm 2.0^{\mathrm{b}}$ \\
\hline & 0.02 & $86.5 \pm 0.5^{\mathrm{aA}}$ & $0.07 \pm 0.01^{\mathrm{aA}}$ & $283.6 \pm 1.9^{\mathrm{bc}}$ & $0.19 \pm 0.01^{\mathrm{ac}}$ & $-16.1 \pm 1.2^{\mathrm{bc}}$ \\
\hline & 0.04 & $93.5 \pm 2.8^{\mathrm{bA}}$ & $0.14 \pm 0.01^{\mathrm{bA}}$ & $284.3 \pm 6.2^{\mathrm{c}}$ & $0.17 \pm 0.01^{\mathrm{abc}}$ & $-16.4 \pm 1.2^{\mathrm{bc}}$ \\
\hline & 0.06 & $93.2 \pm 2.6^{\mathrm{bA}}$ & $0.21 \pm 0.01^{\mathrm{cA}}$ & $277.2 \pm 7.3^{\mathrm{bc}}$ & $0.17 \pm 0.01^{\mathrm{abc}}$ & $-16.3 \pm 0.7^{\mathrm{bc}}$ \\
\hline & 0.08 & $96.1 \pm 0.1^{\mathrm{bB}}$ & $0.29 \pm 0.01^{\mathrm{dA}}$ & $276.9 \pm 3.8^{\mathrm{bc}}$ & $0.17 \pm 0.01^{\mathrm{bc}}$ & $-19.2 \pm 0.7^{\mathrm{ac}}$ \\
\hline \multirow[t]{6}{*}{ Nano } & 0 & - & - & $93.6 \pm 2.2^{\mathrm{a}}$ & $0.21 \pm 0.01^{\mathrm{a}}$ & $-18.5 \pm 1.4^{\mathrm{ab}}$ \\
\hline & 0.01 & ND & ND & $91.1 \pm 4.0^{\mathrm{a}}$ & $0.26 \pm 0.01^{\mathrm{b}}$ & $-16.5 \pm 1.6^{\mathrm{a}}$ \\
\hline & 0.02 & $84.5 \pm 3.2^{\mathrm{aA}}$ & $0.15 \pm 0.02^{\mathrm{aB}}$ & $94.2 \pm 3.9^{\mathrm{a}}$ & $0.26 \pm 0.01^{\mathrm{b}}$ & $-16.6 \pm 1.3^{\mathrm{a}}$ \\
\hline & 0.04 & $84.8 \pm 0.7^{\mathrm{aB}}$ & $0.29 \pm 0.02^{\mathrm{bB}}$ & $97.2 \pm 6.2^{\mathrm{a}}$ & $0.24 \pm 0.01^{\mathrm{b}}$ & $-16.4 \pm 1.2^{\mathrm{a}}$ \\
\hline & 0.06 & $88.3 \pm 0.6^{\mathrm{aB}}$ & $0.44 \pm 0.01^{\mathrm{cB}}$ & $100.3 \pm 6.4^{\mathrm{a}}$ & $0.22 \pm 0.01^{\mathrm{a}}$ & $-15.8 \pm 1.1^{\mathrm{a}}$ \\
\hline & 0.08 & $98.0 \pm 0.9^{\mathrm{bB}}$ & $0.61 \pm 0.05^{\mathrm{dB}}$ & $94.7 \pm 4.8^{\mathrm{a}}$ & $0.21 \pm 0.01^{\mathrm{a}}$ & $-20.2 \pm 2.6^{\mathrm{b}}$ \\
\hline
\end{tabular}

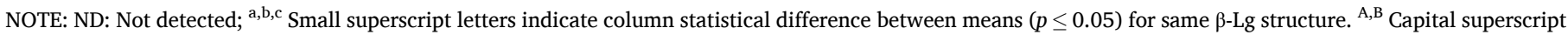
letters indicate column statistical difference between means $(p \leq 0.05)$ for different $\beta$-Lg structures. 
other hand, in terms of $L C$, it is possible to observe that both $\beta$-Lg microand nanostructures displayed a lower capacity to load quercetin (i.e., up $0.61 \%$ ) then riboflavin (i.e., up to $1.80 \%$ ). This difference could be attributed to the molecular weight, water solubility and chemical structure of the bioactive model compounds employed.

Overall, the $\beta$-Lg nanostructures showed higher $L C$ values $(p \leq 0.05)$ for riboflavin (Table 1 ) and quercetin (Table 2 ) in comparison with $\beta$-Lg microstructures. This may be related to the higher surface area-tovolume ratio of nanoscale structures, which may be able to bind higher levels of bioactive compounds (Jafari \& McClements, 2017).

In terms of particle sizes, it is possible to observe from Table 2 that $\beta$-Lg microstructures significantly increased $(p \leq 0.05)$ the particle sizes (monomodal distribution) as the quercetin concentration increases. The change in particle size values of $\beta$ - $\mathrm{Lg}$ microstructures as affected by quercetin concentration may be related to two possible phenomena that may be occurring: protein-polyphenol interaction; and/or surface charge-modulated structural changes, for instance, flexibility, specific surface (Mirpoor et al., 2017).

Nonetheless, it was found that the association of both bioactive model compounds did not affect significantly $(p>0.05)$ the $\beta$-Lg nanostructures' particle sizes, which have a monomodal distribution with relatively low PDI values (PDI $<0.26$ ). Further, the incorporation of quercetin into $\beta$ - $\mathrm{Lg}$ micro- and nanostructures gradually shifted the surface charge as the concentration of quercetin increased up to 0.06 $\mathrm{mg} \mathrm{mL}^{-1}$, thus suggesting conformational rearrangements of $\beta$ - $\mathrm{Lg}$ structures with the quercetin association. However, for quercetin concentration of $0.08 \mathrm{mg} \mathrm{mL}^{-1}$, the values of surface charge for $\beta-\mathrm{Lg}$ / quercetin micro- and nanostructures become similar to those exhibited by $\beta$-Lg structures without quercetin. This behaviour may indicate that higher quercetin concentrations $\left(\geq 0.08 \mathrm{mg} \mathrm{mL}^{-1}\right.$ ) may be able to promote conformational rearrangements on $\beta$-Lg structures with the establishment of stable electrostatic interactions capable of preventing aggregation (Liu et al., 2018).

Based on the best results obtained for the $A E$ and $L C$ and taking into consideration the physicochemical properties evaluated by DLS and discussed above, and in order to minimize the number of experimental tests to be performed, the concentration of $0.105 \mathrm{mg} \mathrm{mL}^{-1}$ of riboflavin and $0.08 \mathrm{mg} \mathrm{mL}^{-1}$ of quercetin were selected to associate to $\beta$-Lg microand nanostructures in the subsequent assays.

\subsection{Morphology}

The shape and size of $\beta$-Lg micro- and nanostructures associated with riboflavin and quercetin bioactive compounds are shown in Fig. 1.

Fig. 1 shows images of $\beta$-Lg micro- (Fig. 1A and 1B) and nano (Fig. 1C and 1D) structures. Measurements from images of $\beta$ - $\mathrm{Lg} /$ riboflavin microstructures (Fig. 1A) and $\beta$ - $\mathrm{Lg} /$ quercetin microstructures (Fig. 1B) revealed an average particle size of ca. 152.0 and $142.3 \mathrm{~nm}$, respectively. DLS results demonstrated higher particle sizes than those obtained by TEM. This difference between both techniques may be due to a drying effect caused by samples preparation for TEM visualization, which may lead to the reduction of particle size. This phenomenon has been equally reported by other authors (Bourbon et al., 2016; Zhang et al., 2018). $\beta$ - $\mathrm{Lg} /$ riboflavin nanostructures (Fig. 1C) and $\beta$ - Lg/quercetin nanostructures (Fig. 1D) showed particle sizes around 75.6 and $76.1 \mathrm{~nm}$, respectively, which corroborates the results obtained by DLS. These results are in agreement with those reported by Liu et al. (2018), which showed homogenous $\beta$ - $\mathrm{Lg} /$ astaxanthin nanoparticles characterized by a spherical and uniform shape, with particle sizes below $100 \mathrm{~nm}$ (i.e. ca. $40 \mathrm{~nm}$ ).

\subsection{Binding properties}

\subsubsection{Extrinsic fluorescence}

The accessibility and conformational changes of protein hydrophobic regions were detected through the binding of the fluorescence
A

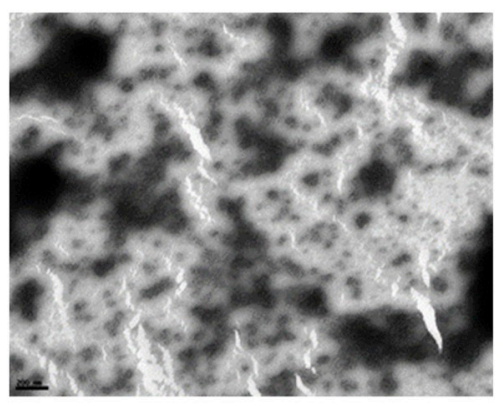

B

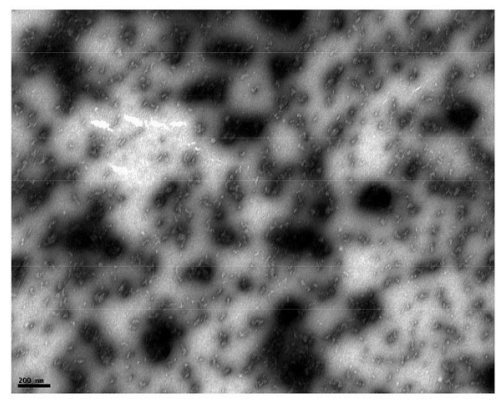

C

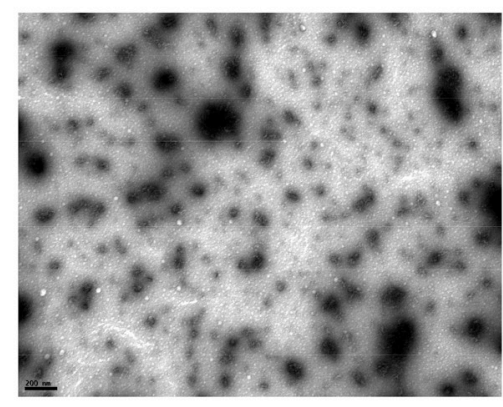

D

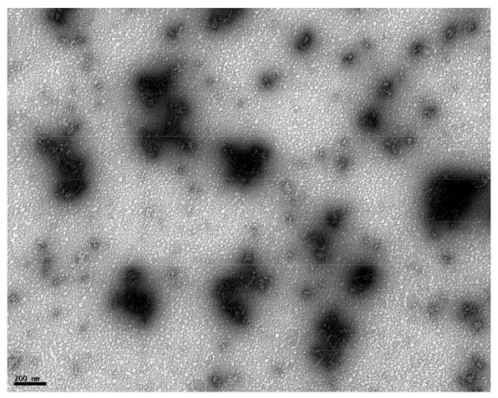

Fig. 1. TEM images of $\beta$ - $\mathrm{Lg} /$ riboflavin microstructures $\mathrm{A}), \beta-\mathrm{Lg} /$ quercetin microstructures B), $\beta$ - $\mathrm{Lg}$ /riboflavin nanostructures $\mathrm{C}$ ), $\beta$ - $\mathrm{Lg}$ /quercetin nanostructures D) (scale bar $=200 \mathrm{~nm}$, magnification $=50.000 \mathrm{x}$ ).

hydrophobic probe ANS (Singh, Hussain, Mishra, \& Akhtar, 2019). According to the literature, $\beta$-Lg exhibit two different binding ANS sites, being located internally (i.e. in the hydrophobic protein core), which contain disulphide bridges; and at externally (i.e., close to the hydrophobic patch on the protein surface), being responsible for nonspecific ANS interaction (Aprodu et al., 2017; Collini, D'Alfonso, \& Baldini, 2009). The ANS interactions with $\beta$ - $\mathrm{Lg}$ micro- and nanostructures, in the 
absence or presence of bioactive compounds, are depicted in Fig. 2.

Extrinsic fluorescence spectra (Fig. 2) showed a maximum peak at a wavelength of $470 \mathrm{~nm}$, which corresponds to $\beta$ - Lg hydrophobic sites. The binding of riboflavin and quercetin with $\beta$ - $\mathrm{Lg}$ micro- and nanostructures led to a loss of signal intensity, thus suggesting that some interactions occurred at the protein hydrophobic regions, competing with ANS binding (Zhang et al., 2018). These results are in accordance with the observations reported by Bourbon, Cerqueira, et al. (2016) and Bourbon, Pinheiro, et al. (2016), which obtained a decrease of peak intensity in lactoferrin-glycomacropeptide nanohydrogels with the encapsulation of curcumin and caffeine (Bourbon et al., 2016).

However, two different behaviours were observed among $\beta$-Lg micro- and nanostructures. While at microscale the binding of quercetin promoted a decrease of the peak intensity, when compared with riboflavin, at nanoscale it was observed a similar fluorescence intensity for both bioactive model compounds. This difference may be related with the fact that for $\beta$ - $\mathrm{Lg} /$ riboflavin microstructures the $A E$ reached its maximum $(64.4 \pm 0.8 \%)$ for the highest concentration of riboflavin tested (i.e., $0.105 \mathrm{mg} \mathrm{mL}^{-1}$ ), so most probably there were still sites available for ANS binding, whereas for $\beta$ - $\mathrm{Lg} /$ riboflavin nanostructures the maximum $A E$ was attained for a riboflavin concentration of 0.014 $\mathrm{mg} \mathrm{mL}{ }^{1}$, which may suggest that all binding sites were occupied by riboflavin, and thus not available to bind to ANS.

Another possible explanation for this observation is that riboflavin has affinity to bind initially to $\beta$ - $\mathrm{Lg}$ through hydrogen and electrostatic interactions, and consequently enable that some hydrophobic patches are available to binding with ANS (Li et al., 2019). However, besides hydrogen and electrostatic interactions and due to the high surface area-volume ratio, $\beta$ - $\mathrm{Lg} /$ riboflavin nanostructures also have the capability to block hydrophobic patches available on the protein surface. This could also be the explanation for the higher $L C$ obtained for $\beta$ - $\mathrm{Lg} /$ riboflavin nanostructures (Table 1 ) when compared with $\beta$ - $\mathrm{Lg} / \mathrm{ri}$ boflavin microstructures for the same concentration of the hydrophilic bioactive compound.

\subsubsection{Circular dichroism}

A Far-UV CD spectra (190-260 nm) were used to analyse protein structural transitions due to the fact that $\beta$-Lg interactions with small ligands may lead to relevant changes in the $\beta$-Lg secondary structure (Liang, Tajmir-Riahi, \& Subirade, 2008). $\beta$-Lg secondary structure have a characteristic $\mathrm{CD}$ spectrum according to their major elements, i.e., an $\alpha$-helix (positive band at $190 \mathrm{~nm}$ and negative peaks at 208 and $220 \mathrm{~nm}$ ), an $\beta$-sheet (negative peak in the $215 \mathrm{~nm}$ region) and a random coil (positive peak at $215 \mathrm{~nm}$ and negative band near $200 \mathrm{~nm}$ ). Thus, it is crucial to investigate the impact of riboflavin and quercetin on the secondary structures of $\beta$ - $\mathrm{Lg}$ in micro- and nanostructures (Essemine, Hasni, Carpentier, Thomas, \& Tajmir-Riahi, 2011; Gomaa, Nsonzi, Sedman, \& Ismail, 2016).

Far UV-CD spectra (Fig. 3) of $\beta$-Lg microstructures showed a negative peak with a minimum at $218 \mathrm{~nm}$, which reveals the presence of $\beta$-sheet structures (characteristic at $215 \mathrm{~nm}$ ) and the presence of $\alpha$-helix

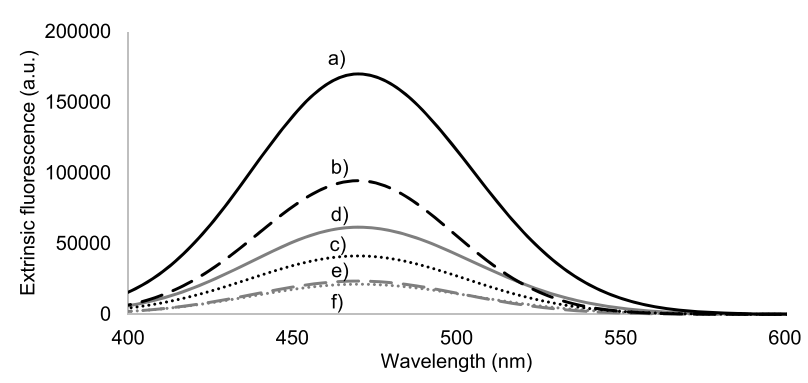

Fig. 2. Extrinsic fluorescence emission spectra at $370 \mathrm{~nm}$ of microstructures: $\beta$ - $\mathrm{Lg}$ a); $\beta$ - $\mathrm{Lg} /$ riboflavin b); and $\beta$ - $\mathrm{Lg}$ /quercetin c); and of nanostructures: $\beta$ - $\mathrm{Lg}$ d); $\beta$-Lg/riboflavin e); $\beta$-Lg/quercetin $\mathrm{f}$ ).

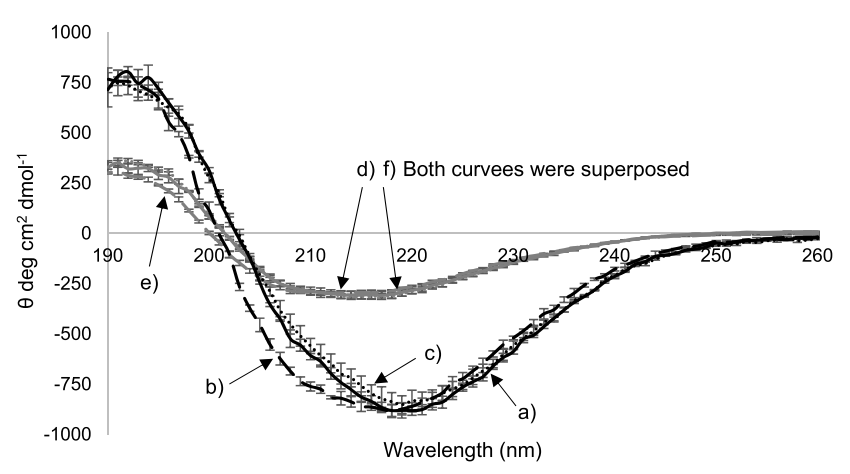

Fig. 3. Far-UV CD spectra (190-260 nm) of microstructures: $\beta-\mathrm{Lg}$ a); $\beta-\mathrm{Lg} /$ riboflavin b); and $\beta$ - $\mathrm{Lg}$ /quercetin c); and of nanostructures: $\beta-\mathrm{Lg} \mathrm{d}$ ); $\beta$ - $\mathrm{Lg}$ / riboflavin e); $\beta$-Lg/quercetin $\mathrm{f}$ ).

conformation due to the band near $220 \mathrm{~nm}$. $\beta$ - $\mathrm{Lg}$ nanostructures displayed a conformational profile with an anti-parallel $\beta$-structure with a broad negative minimum at $214 \mathrm{~nm}$.

The CD spectra of $\beta$ - $\mathrm{Lg}$ /quercetin micro- and nanostructures were superposed with the corresponding structures of isolated $\beta$-Lg. This finding indicates that interaction between quercetin and $\beta$-Lg did not cause changes in the protein secondary structure; however, this evidence should be confirmed by other complementary techniques. On the other hand, for far-UV spectra of $\beta$ - $\mathrm{Lg} /$ riboflavin micro- and nanostructures, it was observed a slight red shift (from 202 to $200 \mathrm{~nm}$ for micro- and from 201 to $200 \mathrm{~nm}$ for nanostructures), thus suggesting that riboflavin chromophoric groups were exposed to the hydrophilic environment.

\subsubsection{Fourier-transform infrared spectroscopy}

The FTIR spectra of $\beta$ - $\mathrm{Lg} /$ riboflavin (Fig. 4A) and $\beta$ - $\mathrm{Lg} /$ quercetin (Fig. 4B) micro- and nanostructures were evaluated in terms of their protein secondary structure and main functional groups present.

Protein conformational changes in the secondary structure are related with amide I band ranging between 1700 and $1600 \mathrm{~cm}^{-1}$ and amide II band around $1530 \mathrm{~cm}^{-1}$ (Xu et al., 2019). As shown in Fig. 4A (a, d) for the $\beta$ - $\mathrm{Lg}$ microstructures and in Fig. 4B (a, d) for the $\beta-\mathrm{Lg}$ nanostructures, both amide I (mainly $\mathrm{C}=\mathrm{O}$ stretch) and amide II (C-N stretch coupled with $\mathrm{N}-\mathrm{H}$ bending mode) increased in intensity with the association of riboflavin - Fig. 4A (b, e) or quercetin - Fig. 4B (b, e), independently of the structures' scale used. These changes have been reported in the literature as conformational changes in the $\beta$-sheet structure, thus suggesting that the association of both bioactive model compounds led to relevant perturbations on the secondary structure of the protein. The association of such bioactive compounds may also cause some disturbances in the tertiary structure of the protein, resulting from rearrangement of hydrophobic interactions, hydrogen and ionic bonds (Ramos et al., 2014).

FTIR spectra of free riboflavin presented an absorption band between 3571 and $2974 \mathrm{~cm}^{-1}$ attributed to -OH stretch, and peaks at 1731 and $1542 \mathrm{~cm}^{-1}$ corresponding to the carbonyl stretching vibration of the amide group and to $-\mathrm{CH}_{3}$ stretching, respectively, as depicted in Fig. 4A (c). Besides, the peak assigned at $848 \mathrm{~cm}^{-1}$ can be ascribed as out-ofplane $\mathrm{N}-\mathrm{H}$ wagging vibration from the pyrimidine ring (Orsuwan, Kwon, Bumbudsanpharoke, \& Ko, 2019; Ye, Woo, \& Selomulya, 2019). In addition, $\mathrm{C}-\mathrm{O}$ stretching appeared in two different absorption bands at 1072 and $1014 \mathrm{~cm}^{-1}$ (Mansour, Abdel-Fattah, \& Soliman, 2014).

In Fig. $4 \mathrm{~A}$, comparing $\beta$ - $\mathrm{Lg} /$ microstructures (a) to $\beta-\mathrm{Lg} /$ riboflavin microstructures (b), it is possible to observe a band shift from 1654 to $1643 \mathrm{~cm}^{-1}$ ( $\mathrm{C}=\mathrm{O}$ stretching) and from 1527 to $1539 \mathrm{~cm}^{-1}\left(-\mathrm{CH}_{3}\right.$ stretching), promoted by the association of riboflavin. The intensities of $\mathrm{C}-\mathrm{O}$ stretching (present at 1161 and $1068 \mathrm{~cm}^{-1}$ ) and of out-of-plane $\mathrm{N}-\mathrm{H}$ wagging vibration (present at $864 \mathrm{~cm}^{-1}$ ), characteristic of $\beta-\mathrm{Lg}$ 
A

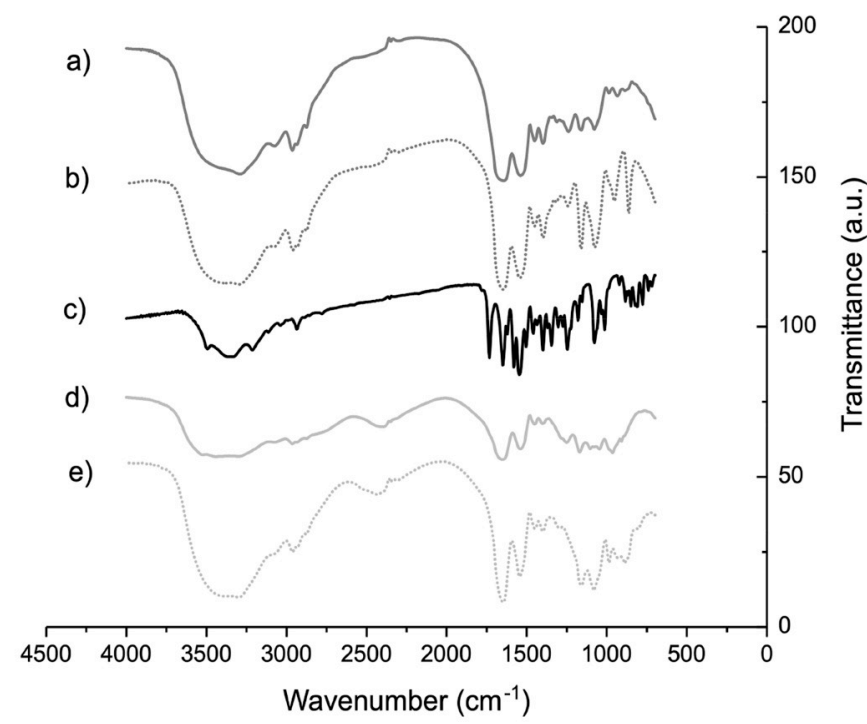

B

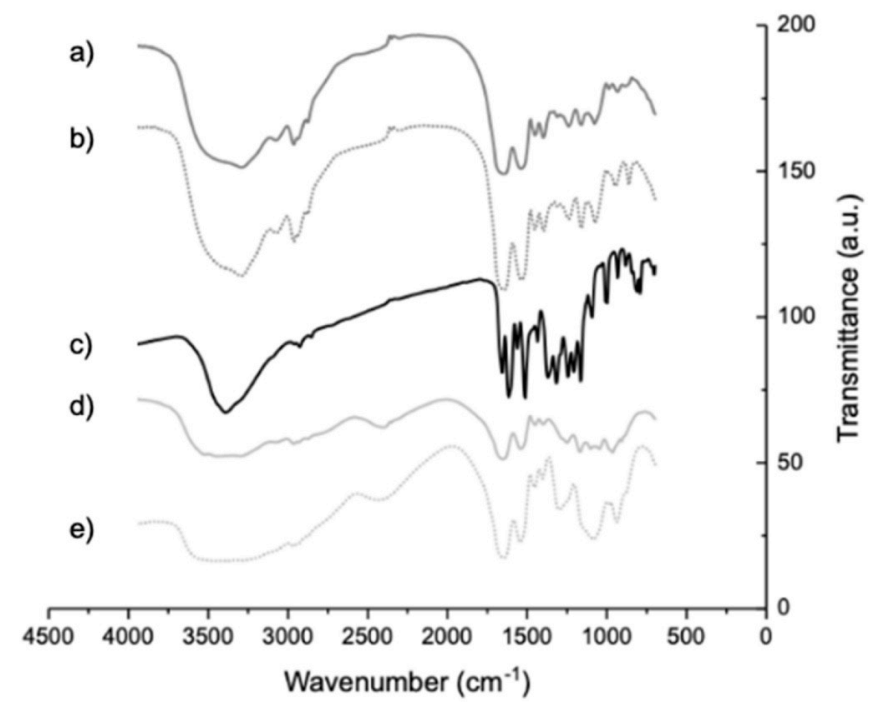

Fig. 4. FTIR spectra of $\beta-\mathrm{Lg} /$ riboflavin micro- and nanostructures $\mathrm{A}$ ) and $\beta-\mathrm{Lg} /$ quercetin micro- and nanostructures B), being a) $\beta$-Lg microstructures; b) $\beta$-Lg microstructures associated with respective bioactive model compound; $c$ ) free bioactive model compound; d) $\beta$ - $\mathrm{Lg}$ nanostructures; and e) $\beta$ - $\mathrm{Lg}$ nanostructures associated with respective bioactive model compound.

structure, increased in $\beta$ - $\mathrm{Lg} /$ riboflavin microstructures.

For $\beta-\mathrm{Lg} /$ riboflavin nanostructures (e), it was also observed a shift in stretching vibration of $\mathrm{C}=\mathrm{O}$ (from 1531 to $1542 \mathrm{~cm}^{-1}$ ) and in $-\mathrm{CH}_{3}$ stretching (from 1650 to $1647 \mathrm{~cm}^{-1}$ ), as well as an increase in the intensity of peaks at 1157 and $1080 \mathrm{~cm}^{-1}$ (mainly C-O stretch) and in the region from 3571 to $2974 \mathrm{~cm}^{-1}$, which may be attributed to the establishment of hydrogen bonds. Riboflavin has a hydrophobic extremity (due the presence of an aromatic ring), which enables binding to $\beta$ - $\mathrm{Lg}$ through hydrophobic bonds; and a hydrophilic group (due to the ribitol chain and pyrimidine ring), which allows the interaction to $\beta$-Lg by hydrogen and electrostatic bonding (Morrison, Connon, \& Khutoryanskiy, 2013; Zhang et al., 2016). These findings were consistent with our $\beta$ - $\mathrm{Lg} /$ riboflavin micro- and nanostructure $L C$ results.

FTIR spectra of free quercetin - Fig. 4B (c) exhibited bands in 3394 $\mathrm{cm}^{-1}$ region, which is attributed to $\mathrm{O}-\mathrm{H}$ stretching vibration of hydroxyl group and aromatic groups (Li et al., 2019), $\mathrm{C}=\mathrm{O}$ stretching (at 1658 $\mathrm{cm}^{-1}$ ), $\mathrm{C}=\mathrm{C}$ stretching (at $1515 \mathrm{~cm}^{-1}$ ), $\mathrm{C}-\mathrm{O}$ aromatic stretching (at $1315 \mathrm{~cm}^{-1}$ ) and an aromatic bending and stretching (at $\left.810 \mathrm{~cm}^{-1}\right)(\mathrm{Ma}$ et al., 2018; Patel, Heussen, Hazekamp, Drost, \& Velikov, 2012).

As shown in Fig. 4B (b), FTIR spectra of $\beta$ - $\mathrm{Lg}$ /quercetin microstructures revealed characteristic bands of free quercetin with a peak intensity increase at $1650 \mathrm{~cm}^{-1}\left(\mathrm{C}=\mathrm{O}\right.$ stretch), $1164 \mathrm{~cm}^{-1}$ (aromatic bending and stretching) and at $856 \mathrm{~cm}^{-1}$ (aromatic bending and stretching). The peak in free quercetin at $3394 \mathrm{~cm}^{-1}$ related to O-H stretching vibration of the hydroxyl group, was shifted from $3278 \mathrm{~cm}^{-1}$ in $\beta$ - $\mathrm{Lg}$ microstructures to $3290 \mathrm{~cm}^{-1}$ in $\beta$ - $\mathrm{Lg}$ /quercetin microstructures. The broader peak of free quercetin suggests that hydrogen bonding was one of the main interactions involved in the binding to $\beta$ - $\mathrm{Lg}$ microstructure. This evidence is in agreement with Shpigelman et al. (2012) findings that indicate that polyphenols may interact with protein partially by hydrogen bonds.

The differences on the FTIR spectra of $\beta$ - $\mathrm{Lg}$ nanostructures - Fig. 4B (d) when compared with $\beta$ - $\mathrm{Lg}$ /quercetin nanostructures - Fig. 4B (e) are mainly due to the progressive increase of peaks at $1647 \mathrm{~cm}^{-1}$, corresponding to $\mathrm{C}=\mathrm{O}$ stretch, at $1307 \mathrm{~cm}^{-1}$ due to $\mathrm{C}-\mathrm{O}$ aromatic stretching, and at $933 \mathrm{~cm}^{-1}$ attributed to aromatic bending and stretching. Moreover, the band in the region of $3394 \mathrm{~cm}^{-1}$ associated to the presence of hydroxyl group and aromatic groups was not obtained for $\beta$ - $\mathrm{Lg}$ /quercetin nanostructures, thus suggesting that hydrogen bonding was not the main binding interactions occurring between quercetin and $\beta$-Lg structures at the nanoscale.

\section{4. $\beta$-Lg structures stability under various environmental conditions}

The effect of several environmental conditions (e.g., $\mathrm{pH}$, temperature, ionic strength, and storage temperature) on $\beta$ - $\mathrm{Lg}$ micro- and nanostructures associated with bioactive compounds was assessed to provide information about the food product characteristics that facilitate their incorporation.

\subsection{1. $p H$ stability}

The effect of $\mathrm{pH}$ was evaluated by adjusting aqueous solutions of $\beta$ - $\mathrm{Lg}$ micro- and nanostructures (data were available in the Supplementary Material, Table S1 and Table S2, respectively) structures to various $\mathrm{pH}$ values in order to assess its impact on their particle size, PDI and surface charge (S). Taking in consideration the $\beta$-Lg isoelectric point (pI), which is near $\mathrm{pH}=4.8$ (Ramos et al., 2012), the zeta potential of aqueous solutions of $\beta$ - $\mathrm{Lg}$ micro- and nanostructures shifted from positive values, at $\mathrm{pH} 2$, towards negative values, at $\mathrm{pH} 10$ (Table S1 and Table S2). At $\mathrm{pH}$ values near the $\mathrm{pI}$ of $\beta$ - $\mathrm{Lg}$, aggregates with large mean particle sizes (i.e., $>5 \mu \mathrm{m}$ ) and white appearance were obtained, independently of the structures' scale. This result is somehow expected since at pI the electrostatic repulsions become weak and proteins tend to aggregate and/or flocculate, forming structures with larger sizes (Ramos et al., 2013).

Chen, Zheng, McClements, and Xiao (2014) evaluated the pH stability, from 3 to 7 , of zein/ $\beta$ - $\mathrm{Lg}$ nanoparticles encapsulating tagerentin (i.e., low water solubility compound), showing aggregation phenomena for such nanoparticles complex for $\mathrm{pH}$ values between 4.5 and 5.5, and high stability for $\mathrm{pH}$ above 5.5 or below 4.5.

The particle diameter of $\beta-\mathrm{Lg}$ micro- and nanostructures with/ without bioactive model compounds remained constant $(p>0.05)$ (Table S1 and Table S2) with low PDI values (i.e., below 0.25 ) for $\mathrm{pH}$ range between 2 and 3 (Table S1 and Table S2). According to the literature, $\beta-\mathrm{Lg}$ structure has stability and remains mostly intact in acid conditions (Liang \& Subirade, 2012; Shafaei et al., 2017). For pH conditions between 6 and 10, particle size and PDI are stable, which may be attributed to the formation of strong covalent or hydrophobic bonds among $\beta$-Lg molecules and bioactive model compounds during thermal 
gelation (Bengoechea, Peinado, \& McClements, 2011).

These results suggest that $\beta$ - $\mathrm{Lg}$ micro- and nanostructures may be suitable carriers for riboflavin and quercetin into soft drinks (with $\mathrm{pH}$ values ranging from 2 to 3 ) and into some dairy products (with $\mathrm{pH}$ values between 6 and 9), and also effective delivery systems upon oral intake since they resist to the acid environment, which is characteristic of the human stomach.

\subsubsection{Ionic strength stability}

The impact of ionic strength on properties of $\beta$ - $\mathrm{Lg}$ micro- and nanostructures was evaluated in order to estimate their behaviour in aqueous commercial products composed by distinct types and amounts of electrolytes, as well as within the human gastrointestinal tract (Chen et al., 2014).

The ionic strength study was carried out by solubilizing $\beta$-Lg microand nanostructures in various concentrations of sodium chloride $(\mathrm{NaCl})$, in order to evaluate the ionic strength effect on particle size and PDI (data were present in the Supplementary Material, Table S3 and Table S4, respectively). Results demonstrated that $\beta$-Lg structures displayed particle sizes in the nanoscale range (i.e., $104.3 \pm 5.9 \mathrm{~nm}$ ) when added to $\mathrm{NaCl}$ until $100 \mathrm{mmol} \mathrm{L}^{-1}$, and remained homogenous (i.e., $\mathrm{PDI}<0.22)$ at this scale-range. The association of riboflavin was able to maintain $\beta$-Lg structures homogeneous and within the nanoscale at $\mathrm{NaCl}$ concentrations up to $200 \mathrm{mmol} \mathrm{L}^{-1}$; PDI values were ranging from $0.21 \pm 0.01$ to $0.22 \pm 0.01$ and particles sizes were ranging from $77.4 \pm 8.2 \mathrm{~nm}$ to $73.9 \pm 6.9 \mathrm{~nm}(p>0.05)$. On the other hand, the addition of $\mathrm{NaCl}$ at concentrations $\leq 25 \mathrm{mmol} \mathrm{L}^{-1}$ did not impact the stability of $\beta$ - Lg nanostructures showing a particle size in the nano range (i.e., $77.9 \pm 9.6 \mathrm{~nm}$ ). However, for progressively higher concentrations of $\mathrm{NaCl}$, the particle sizes of $\beta-\mathrm{Lg}$ /quercetin nanostructures increased significantly $(p \leq 0.05)$ above $100 \mathrm{~nm}$, and structures became more heterogeneous. According to Bourbon et al. (2015), the presence of $\mathrm{NaCl}$ may impacts the size and PDI of protein structures by two different mechanisms: i) by promoting the establishment of attractive interactions, for instance, van der Waals or hydrophobic, which dominate the repulsive interactions; or ii) by modifying the organization of structural water molecules, which changes the strength of hydrophobic interactions between nonpolar groups.

Regarding the impact of ionic strength, the addition of $\mathrm{NaCl}$ at concentrations $\leq 200 \mathrm{mmol} \mathrm{L}^{-1}$ did not impact the stability (i.e., particle size and $\mathrm{PDI}$ ) of $\beta$ - $\mathrm{Lg}$ /quercetin microstructures, however higher concentrations of $\mathrm{NaCl}$ increased significantly $(p \leq 0.05)$ its particle size $(383.8 \pm 26.6 \mathrm{~nm})$ and PDI $(0.28 \pm 0.03)$ values. This result may indicate that at higher (i.e., micro-) scale range the $\mathrm{Na}^{+}$and $\mathrm{Cl}^{-}$ions may have a lower impact on $\beta$-Lg microstructures, since as the surface-tovolume ratio is lower than that in nanostructures, $\beta$ - Lg is less subjected to the action of $\mathrm{NaCl}$, and thus a higher concentration of salt is needed to neutralize $\beta$-Lg's charge and to reduce electrostatic repulsion
(Hu \& McClements, 2014).

These results suggest that $\beta-\mathrm{Lg} /$ riboflavin nanostructures, and $\beta-\mathrm{Lg} /$ riboflavin and $\beta$ - $\mathrm{Lg}$ /quercetin microstructures are suitable delivery systems for a large variety of food systems since they are stable at a relatively broad range of salt concentrations. Additionally, they also should be stable in the gastrointestinal tract during digestion when considering this parameter, since the normal ionic strength in the stomach is $100 \mathrm{mmol} \mathrm{L}^{-1}$ and in the small intestine is $140 \mathrm{mmol} \mathrm{L}^{-1}$ (McClements \& Li, 2010; Pinheiro, Gonçalves, Madalena, \& Vicente, 2017).

\subsubsection{Thermal stability}

Heating is a common processing treatment in the food industry, therefore it is crucial to evaluate the thermal stability of delivery systems at a temperature range of at least $20-80{ }^{\circ} \mathrm{C}$. Therefore, the effect of temperature on $\beta$-Lg micro- and nanostructures (data were available in the Supplementary Material, Table S5 and Table S6, respectively) properties was investigated at those conditions. The particle size of $\beta-\mathrm{Lg}$ micro- and nanostructures in the absence and presence of bioactive compounds did not change $(p>0.05)$ for temperatures below $70{ }^{\circ} \mathrm{C}$ and slightly increased $(p \leq 0.05)$, when subjected to temperatures between 70 and $80{ }^{\circ} \mathrm{C}$. The PDI values of $\beta$ - $\mathrm{Lg}$ structures were below 0.25 , independently of temperature, indicating a good homogeneity of such protein structures within a narrow size distribution. This temperature stability may be due to some changes in the conformational state (Bourbon et al., 2015) or reorganization of $\beta$ - $\mathrm{Lg}$ molecules, without compromising its functionality (Hu \& McClements, 2014). These results are in the same line of those presented in a previous study conducted by Yi et al. (2016), which showed thermal stability of $\alpha$-lactalbu$\mathrm{min} /$ curcumin nano-complexes for temperatures ranging from 30 to 90 ${ }^{\circ} \mathrm{C}$, with a slight increase in particle diameter observed for temperatures above $70{ }^{\circ} \mathrm{C}$.

\subsubsection{Storage}

Temperature is an important condition to preserve the effective quality and benefits of bioactive compounds, thus contributing to physiological wellbeing (Kang, Lee, Kim, \& Chang, 2019; Ramos et al., 2017). Therefore, a storage stability study was performed to assess the effect of temperature at $4{ }^{\circ} \mathrm{C}$ (to simulate refrigerated conditions) and at $25{ }^{\circ} \mathrm{C}$ (to simulate room temperature conditions) over 90 days of storage. $\beta$-Lg microstructures (data were present in Supplementary Material, Table S7) without association of bioactive model compounds maintained their stability in terms of particle size (from $202.5 \pm 5.8 \mathrm{~nm}$ to $202.0 \pm 11.1 \mathrm{~nm}$ ), PDI (from $0.18 \pm 0.02$ to $0.17 \pm 0.01$ ) and surface charge (from $-22.2 \pm 1.9 \mathrm{mV}$ to $-21.4 \pm 1.2 \mathrm{mV}$ ) at the beginning and after 90 days of storage, respectively, at $4{ }^{\circ} \mathrm{C}$; while at $25{ }^{\circ} \mathrm{C}$ it was possible to observe the formation of precipitates over 50 days of storage, indicating loss of colloidal stability.

Table 3

Linear superimposition model (LSM) fitting of riboflavin and quercetin release data from $\beta$-Lg micro- and nanostructures. The parameters RMSE and $R^{2}$ were used to evaluate the quality of the regression.

\begin{tabular}{|c|c|c|c|c|c|c|c|c|}
\hline Bioactive compound & $\beta$ - Lg Structure & Food Simulant & $\mathrm{T}\left({ }^{\circ} \mathrm{C}\right)$ & RMSE & $R^{2}$ & $x$ & $K_{F}\left(\min ^{-1}\right)$ & $K_{R}\left(\min ^{-1}\right)$ \\
\hline \multirow{6}{*}{ Riboflavin } & & & 25 & 0.03 & 0.99 & 0.08 & 6.08 & 0.80 \\
\hline & & $50 \%$ ethanol & 4 & 0.10 & 0.99 & 0.09 & 2.92 & 0.25 \\
\hline & Nano & $10 \%$ ethanol & 4 & 0.07 & 0.99 & 0.06 & 3.63 & 0.36 \\
\hline & & & 25 & 0.02 & 0.99 & 0.03 & 6.29 & 1.15 \\
\hline & & $50 \%$ ethanol & 4 & 0.06 & 0.97 & 0.06 & 0.01 & 0.27 \\
\hline & & & 25 & 0.11 & 0.99 & 0.10 & 8.37 & 1.10 \\
\hline \multirow{2}{*}{ Quercetin } & & $50 \%$ ethanol & 4 & 0.03 & 0.99 & 0.06 & 0.09 & 0.10 \\
\hline & & & 25 & 0.02 & 0.99 & 0.01 & 2.74 & 0.80 \\
\hline
\end{tabular}

NOTE: T: Temperature; RMSE: Root Mean Square Error; $X$ : Bioactive compound fraction released by Fickian transport; $K_{F}$ : Fick rate constant; $K_{R}$ : relaxation rate constant. 
$\beta$-Lg nanostructures (data were available in Supplementary Material, Table S8) without the association of bioactive model compounds were able to maintain their properties without significant changes $(p>0.05)$ in terms of particle size, PDI and surface charge over the storage period, independently of the temperature tested, thus suggesting that $\beta$ - Lg nanostructures were stable and able to retain their structure. These nanostructures displayed higher storage stability when compared with the performance exhibited by $\alpha$-lactalbumin-lysozyme nanoparticles (with sizes of $61.0 \pm 2.3 \mathrm{~nm}$ ), tested by Monteiro et al. (2016). In that case, $\alpha$-lactalbumin-lysozyme nanoparticles were able to maintain their stability over 90 days at $4{ }^{\circ} \mathrm{C}$ but only for 30 days at $25{ }^{\circ} \mathrm{C}$. This difference may be related to the different protein characteristics or to the weak intermolecular interactions established between $\alpha$-lactalbumin-lysozyme.

In terms of stability of $\beta$ - $\mathrm{Lg}$ /quercetin nanostructures, precipitates were formed over 2 days of storage, independently of the storage temperature tested. As mentioned before, quercetin use is limited by its poor water solubility (Ni, Hu, Sun, Zhao, \& Xia, 2017). When ethanolic solutions (used in the solubilization of quercetin) were added into $\beta$-Lg aqueous systems, large precipitates were formed, displaying an atypical needle-like morphology, which is extremely unstable and leads to sedimentation. Despite of this, the precipitates' shape may be controlled by increasing protein concentration, thus leading to a decrease in the appearance of needle-shaped crystals (Patel et al., 2012).

Regarding the stability of $\beta$ - $\mathrm{Lg} /$ riboflavin microstructures (Table S7), they were stable over the 90 days at both temperatures tested. The association of riboflavin was even able to prevent the formation of precipitates observed in $\beta$ - $\mathrm{Lg}$ microstructures isolated after 50 days of storage. This evidence may be due to possible changes promoted by riboflavin at the $\beta$-Lg surface, possibly the establishment of strong interactions that may have prevented the electrostatic attraction between protein molecules. The magnitude of surface charge for $\beta$ - $\mathrm{Lg}$ microstructures with and without bioactive model compounds (Table S7) association did not change significantly $(p>0.05)$ during the storage time, being around $-20.0 \mathrm{mV}$.

$\beta$ - $\mathrm{Lg} /$ riboflavin nanostructures (Table S8) demonstrated a slight change in particle size ranging from $70.8 \pm 2.3 \mathrm{~nm}$ to $78.0 \pm 4.7 \mathrm{~nm}$ with PDI value lower than 0.25 , over 80 days of storage at $4{ }^{\circ} \mathrm{C}$. However, over 90 days, the particle sizes and PDI increased more pronouncedly, reaching $84.3 \pm 8.7 \mathrm{~nm}$ and $0.30 \pm 0.01$, respectively. These results are in line with those reported by Martins et al. (2016), which showed that lactoferrin/iron nanoparticles were stable in terms of particle size and PDI during 76 days at $4{ }^{\circ} \mathrm{C}$.

At $25{ }^{\circ} \mathrm{C}$, the stability of $\beta$ - $\mathrm{Lg} /$ riboflavin nanostructures decreased significantly to 22 days (particles sizes of $67.8 \pm 1.9 \mathrm{~nm}$ and PDI of $0.25 \pm 0.01$ ), when compared with those exhibited over 90 days (particles sizes of $70.5 \pm 1.6 \mathrm{~nm}$, but PDI values of $0.40 \pm 0.10$ ), which may indicate that dissociation or aggregation phenomena occurred after 22 days. This evidence indicates that refrigeration could improve the storage stability of $\beta$ - $\mathrm{Lg}$ micro- and nanostructures loaded with riboflavin and quercetin.

$\beta$ - $\mathrm{Lg} /$ riboflavin micro- and nanostructures and $\beta$ - $\mathrm{Lg}$ /quercetin microstructures showed the best performance in terms of stability for the tests performed above, and for that reason the behaviour of such structures was evaluated into food simulants.

\subsection{In vitro release kinetics}

Release profiles were used to ensure that a delivery system will act according to the designed goal. These profiles are expected to estimate the behaviour of $\beta$-Lg micro- and nanostructures into food products. The release profile of riboflavin and quercetin bioactive compounds from $\beta$ - $\mathrm{Lg}$ micro- and nanostructures added into food simulants (i.e., $10 \%$ of ethanol simulating hydrophilic matrices and $50 \%$ of ethanol simulating hydrophobic matrices) were assessed at $4{ }^{\circ} \mathrm{C}$ (to simulate refrigerated conditions) and at $25{ }^{\circ} \mathrm{C}$ (to simulate room temperatures). The release kinetics of bioactive model compounds from $\beta$ - $\mathrm{Lg}$ micro- and nanostructures were monitored during $72 \mathrm{~h}$. The amount (\%) of bioactive compound released as a function of time is plotted in Fig. 5.

Fig. 5 shows a typical release profile, where the initial $8 \mathrm{~h}$ comprises a burst release stage associated to the faster release of unbound bioactive compounds, followed by a controlled release phase attributed to the behaviour of bioactive compounds bounded to $\beta$ - $\mathrm{Lg}$ micro- and nanostructures or to $\beta$ - $\mathrm{Lg}$ conformational changes under contact with food simulants (Heydari, Mehrabi, Shamspur, Sheibani, \& Mostafavi, 2018). These release profiles are in agreement with other release studies that use proteins as the main encapsulating agent (Liu et al., 2018; Luo, Zhang, Whent, Yu, \& Wang, 2011; Wang, Ren, Ding, Xu, \& Chen, 2018). O'Neill et al. (2015) reported a release of $42 \%$ of riboflavin from whey protein hydrogels within $2 \mathrm{~h}$ in a water matrix at $20^{\circ} \mathrm{C}$. The authors concluded that this delivery system was not suitable for food products with high moisture content stored at room temperature conditions. Kumari, Yadav, Pakade, Singh, and Yadav (2010) developed poly-D, L-lactide nanoparticles for quercetin delivery and reported a rapid burst, releasing $40-45 \%$ of quercetin within $30 \mathrm{~min}$ in $0.1 \mathrm{~mol} \mathrm{~L}^{-1}$ of phosphate-buffered saline (PBS) buffer solution.

In our study, riboflavin and quercetin were rapidly released from $\beta$-Lg micro- and nanostructures when added into a hydrophobic (50\% ethanol) food simulant at $25{ }^{\circ} \mathrm{C}$. This result may be related to the fact that ethanol present at high concentrations (i.e., $50 \%$ ) in contact with $\beta$-Lg may affect the stability of this protein, by promoting irreversible

A

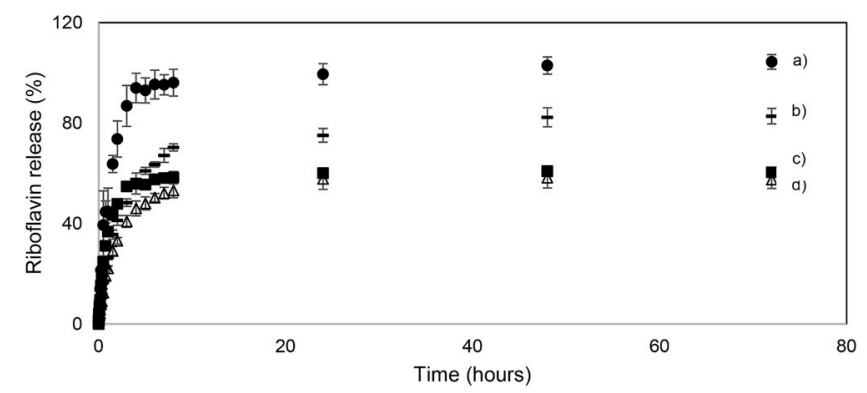

B

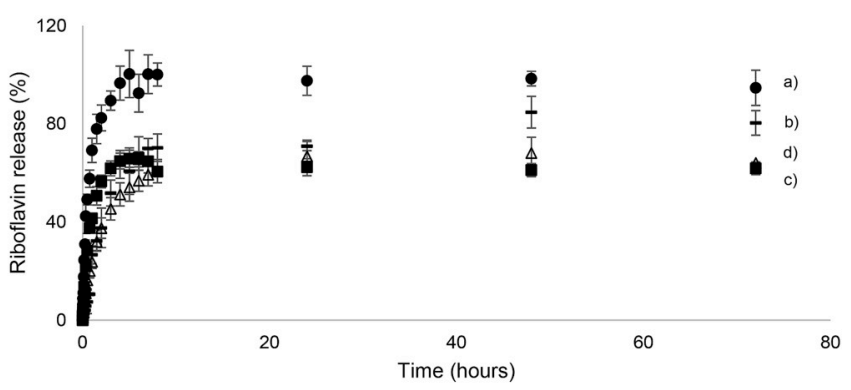

C

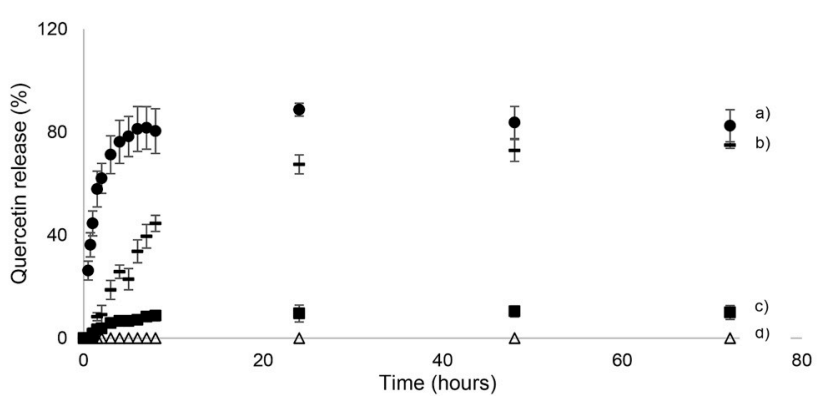

Fig. 5. Release profiles of riboflavin from $\beta-\mathrm{Lg}$ micro- A) and $\beta$ - $\mathrm{Lg}$ nanostructures $\mathrm{B}$ ); and quercetin from $\beta-\mathrm{Lg}$ microstructures $\mathrm{C}$ ), added into the following food simulants: a) $50 \%$ at $25^{\circ} \mathrm{C}$; b) $50 \%$ at $4{ }^{\circ} \mathrm{C}$; c) $10 \%$ at $25^{\circ} \mathrm{C}$ and d) $10 \%$ at $4{ }^{\circ} \mathrm{C}$. 
changes in the protein's secondary structure with consequent protein disintegration (Yoshizawa, Arakawa, \& Shiraki, 2014).

$\beta$-Lg/riboflavin micro- (Fig. 5A) and nanostructures (Fig. 5B) showed a similar release profile when tested in both hydrophilic and hydrophobic food simulants at $4{ }^{\circ} \mathrm{C}$ and $25{ }^{\circ} \mathrm{C}$. Commonly, the "responsiveness" is related to the interactions established between bio-based materials used as carriers and the surrounding environment (Musyanovych \& Landfester, 2014); however, it is essential to determine the mechanism involved in this process, in order to allow the controlled release of bioactive compounds at the micro- and nanoscale.

As shown in Fig. 5C, under hydrophilic food simulant conditions, $\beta$-Lg microstructures practically did not release quercetin at $4{ }^{\circ} \mathrm{C}$, over $72 \mathrm{~h}$. This could be due to the hydrophobic character of quercetin that did not diffuse to the hydrophilic food simulant; thus, it was not possible to describe the release profile of quercetin in these conditions. These results are in agreement with those published by Bourbon, Cerqueira, et al. (2016) and Bourbon, Pinheiro, et al. (2016), which showed that curcumin (hydrophobic compound) was not released from lactoferrin-glycomacropeptide nanohydrogels due the low solubility of curcumin at $\mathrm{pH} 7.3$ in phosphate buffer solution, used as food simulant.

The release kinetics results of both bioactive compounds (Fig. 5) were fitted to a mathematical model - Linear Superimposition Model (LSM) (Equation (7)) - to find the most adequate release mechanism model. The plots of $\beta-\mathrm{Lg}$ /riboflavin micro- (data were present in Supplementary Material, Figure S1), $\beta$ - $\mathrm{Lg} /$ riboflavin nanostructures (data were available in Supplementary Material, Figure S2) and $\beta$-Lg/quercetin microstructures (data were present in Supplementary Material, Figure S3) fitted well with the LSM. Table 3 shows the fitting parameters of LSM to experimental data of riboflavin and quercetin released from $\beta$-Lg micro-and nanostructures.

Results from Table 3 demonstrate that LSM fitted well to data obtained with a $R^{2}>0.98$, thus indicating that this model was suitable to describe the release mechanisms of riboflavin and quercetin from $\beta$-Lg micro- and nanostructures. The model suggests that the transport mechanisms involved can be described by Fick's diffusion and Case II transport (biopolymer relaxation), with one main relaxation of the $\beta$ - $\mathrm{Lg}$ micro- and nanostructures.

Table 3 shows that release kinetics of bioactive compounds can be affected by both food simulants (i.e., with hydrophilic and hydrophobic nature) and temperature (i.e., 4 and $25^{\circ} \mathrm{C}$ ). The relaxation rate constant $\left(K_{R}\right)$ increased with temperature, independently of the food simulant used, which may be attributed to the input of energy into the system that promotes a more relaxed and weaker protein structure, thus increasing the diffusion of the bioactive compound.

In the hydrophilic food simulant (10\% ethanol) the amount of riboflavin released from $\beta$-Lg micro- and nanostructures was higher than that obtained for the hydrophobic counterparts. On the contrary, the quercetin release into hydrophobic food simulant at $25{ }^{\circ} \mathrm{C}$ was higher than that obtained in the hydrophilic environment. These findings might be due the relaxation rate constant value $\left(K_{R}\right)$ and related with the hydrophilic and hydrophobic nature of riboflavin and quercetin, respectively, and with their affinity to diffuse to hydrophilic and hydrophobic food simulants, respectively.

It was found that $\beta$-Lg/bioactive compound micro- and nanostructures exhibited a similar relaxation rate constant for both food simulants at $4{ }^{\circ} \mathrm{C}$. However, in the simulant at room temperature (i.e., 25 ${ }^{\circ} \mathrm{C}$ ) the $\beta$ - Lg nanostructures showed faster release kinetics, confirmed by the high $K_{F}$ obtained, as compared to that of $\beta$ - $\mathrm{Lg}$ microstructures. This behaviour may be related with the higher exposure area as a result of the higher surface-to-volume ratio, characteristic of nanoscale materials, which in association with the effect of temperature $\left(25{ }^{\circ} \mathrm{C}\right)$, has enhanced the protein relaxation and thus an increased riboflavin release.

For most conditions tested, the Fickian $\left(K_{F}\right)$ rate constant was higher than the relaxation $\left(K_{R}\right)$ rate constant, which may be indicating that bioactive compounds release was quicker by Fick's diffusion instead of relaxation mechanism (Martins et al., 2016).

The bioactive compound fraction released by Fickian transport $(X$ value), defined as $\frac{M_{\infty F}}{M_{t}}$, allows determining the governing bioactive compound release mechanism. If $X>0.5$ the prevailing bioactive compound release mechanism is Fickian diffusion, while if $X<0.5$ relaxation is the main mechanism of release (Pinheiro et al., 2012). Therefore, this implies that the release of both bioactive model compounds from $\beta$-Lg micro- and nanostructures is mainly governed by the relaxation mechanism.

Wichchukit, Oztop, McCarthy, and McCarthy (2013) reported that riboflavin release from whey protein beads in a beverage model food exhibited a transport mechanism governed by Case II, which resulted in slow release rates during product shelf life and until its consumption. Yan et al. (2018) investigated the controlled release of quercetin-loaded chitosan nanoparticle into $50 \%$ ethanol and water-oil (50:50) food simulants at $25{ }^{\circ} \mathrm{C}$ and reported an initial burst followed by sustained slow release. These authors described the quercetin release profile as a Fick's curve; however, they did not apply a mathematical model to prove this behaviour.

Table 4 shows $\beta$-Lg micro- and nanostructure properties (i.e., particle size, PDI and S) analysed before and after bioactive compounds (i.e., riboflavin and quercetin) release, and bioactive compounds final concentrations in $\beta$-Lg structures.

Data presented in Table 4 show that $\beta$-Lg micro- and nanostructures increased their particle size $(p \leq 0.05)$ during the release period, for all conditions tested. This behaviour is typical when the release mechanism is governed by biopolymer relaxation and when structures present a swelling behaviour in response to chemical (e.g., $\mathrm{pH}$, solvent and ionic strength) and/or physical (e.g., temperature, light) stimuli (Simões et al., 2017). The swelling capacity of $\beta$ - $\mathrm{Lg}$ micro- and nanostructures may be related with the presence of hydrophilic moieties (e.g., hydroxyl, amino, or carboxyl groups) in their structure (Ramos et al., 2017). This hypothesis is supported by FTIR results, which showed the presence of such hydrophilic groups in $\beta$-Lg's structure. Bourbon, Cerqueira, et al. (2016) and Bourbon, Pinheiro, et al. (2016) also demonstrated that lactoferrin-glycomacropeptide nanohydrogels increased their particle size with the release or curcumin due to the swelling behaviour of nanohydrogels, which is a typical case of release mechanisms dominated by biopolymer relaxation (Bourbon et al., 2016). Nonetheless, the authors obtained small sized nanohydrogel particles when Fick's diffusion was the main release mechanism.

In terms of surface charge, it was possible to observe that $\beta$ - $\mathrm{Lg} /$ bioactive compounds maintained their surface charge constant, with zeta potential values of ca. $-20 \mathrm{mV}$, during release in hydrophilic food simulant conditions, which indicates a relatively stable system. For $\beta$ - $\mathrm{Lg}$ /quercetin microstructures, when they were added to a hydrophobic simulant (in this particular case with a higher content of ethanol), $\beta$-Lg loses its structural stability, as demonstrated by the decrease of the surface charge (Table 4). This effect can be explained by the fact that ethanol molecules affect the repulsive interactions responsible for $\beta$ - $\mathrm{Lg}$ stability (Yoshizawa et al., 2014).

On the other hand, when $\beta$ - $\mathrm{Lg}$ /quercetin microstructures were added to a hydrophilic food simulant (i.e., $10 \%$ ethanol) at $4{ }^{\circ} \mathrm{C}$ it was possible to observe that ca. half of the initial concentration of quercetin was released to the hydrophilic food simulant. Moreover, it was possible to see that temperature had an effect on the release of both bioactive model compounds, as mentioned above. Thus, the hydrophobic characteristics of quercetin and slow release results in hydrophilic food simulants at 25 ${ }^{\circ} \mathrm{C}$, suggest that the combination of a hydrophilic food simulant with the temperature at $4{ }^{\circ} \mathrm{C}$ influences the $\beta$ - $\mathrm{Lg}$ structure relaxation and thus a reduction of quercetin release.

An effective delivery system should be able to release the bioactive compounds associated to it, in a controlled way and for prolonged periods, to the surrounding environment (Wichchukit et al., 2013). $\beta-\mathrm{Lg}$ micro- and nanostructures were able to keep at least $5 \%$ of the initial 
Table 4

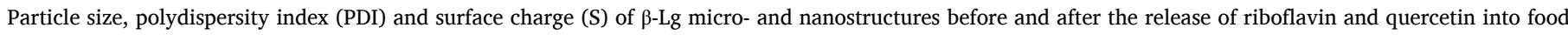
simulants at various temperature $\left(4\right.$ and $25^{\circ} \mathrm{C}$ ), and the bioactive compounds final concentration present in $\beta$ - $\mathrm{Lg}$ structures.

\begin{tabular}{|c|c|c|c|c|c|c|c|c|}
\hline Bioactive compound & $\beta$-Lg Structure & Food Simulant & $\mathrm{T}\left({ }^{\circ} \mathrm{C}\right)$ & & Particle size (nm) & PDI & $\mathrm{S}(\mathrm{mV})$ & Final concentration $\left(\mathrm{mg} \mathrm{mL}^{-1}\right)$ \\
\hline \multirow[t]{16}{*}{ Riboflavin } & \multirow[t]{8}{*}{ Micro } & \multirow[t]{4}{*}{$10 \%$ ethanol } & \multirow[t]{2}{*}{4} & $\mathbf{I}$ & $243.9 \pm 5.8^{\mathrm{a}}$ & $0.25 \pm 0.01^{\mathrm{a}}$ & $-21.3 \pm 1.3^{\mathrm{a}}$ & \multirow[t]{2}{*}{$0.005 \pm 0.001$} \\
\hline & & & & $\mathbf{F}$ & $316.1 \pm 8.0^{\mathrm{b}}$ & $0.25 \pm 0.02^{\mathrm{a}}$ & $-23.2 \pm 0.5^{\mathrm{b}}$ & \\
\hline & & & \multirow[t]{2}{*}{25} & I & $241.8 \pm 1.9^{\mathrm{a}}$ & $0.19 \pm 0.01^{\mathrm{a}}$ & $-19.9 \pm 1.5^{\mathrm{a}}$ & \multirow[t]{2}{*}{$0.007 \pm 0.001$} \\
\hline & & & & $\mathbf{F}$ & $280.9 \pm 8.8 b$ & $0.18 \pm 0.01^{b}$ & $-25.6 \pm 0.9^{\mathrm{b}}$ & \\
\hline & & \multirow[t]{4}{*}{$50 \%$ ethanol } & \multirow[t]{2}{*}{4} & $\mathbf{I}$ & $258.2 \pm 6.5^{\mathrm{a}}$ & $0.23 \pm 0.02^{\mathrm{a}}$ & $-22.0 \pm 1.4^{\mathrm{a}}$ & \multirow[t]{2}{*}{$0.005 \pm 0.001$} \\
\hline & & & & $\mathbf{F}$ & $670.5 \pm 14.5^{\mathrm{b}}$ & $0.18 \pm 0.03^{b}$ & $-10.7 \pm 1.7^{\mathrm{b}}$ & \\
\hline & & & \multirow[t]{2}{*}{25} & I & $249.5 \pm 3.6^{\mathrm{a}}$ & $0.19 \pm 0.01^{\mathrm{a}}$ & $-21.8 \pm 1.3^{\mathrm{a}}$ & \multirow[t]{2}{*}{$0.006 \pm 0.002$} \\
\hline & & & & $\mathbf{F}$ & $680.3 \pm 10.3^{\mathrm{b}}$ & $0.16 \pm 0.04^{\mathrm{a}}$ & $-11.7 \pm 1.2^{\mathrm{b}}$ & \\
\hline & \multirow[t]{8}{*}{ Nano } & \multirow[t]{4}{*}{$10 \%$ ethanol } & \multirow[t]{2}{*}{4} & I & $76.8 \pm 5.1^{\mathrm{a}}$ & $0.25 \pm 0.01^{\mathrm{a}}$ & $-20.4 \pm 1.4^{\mathrm{a}}$ & \multirow{2}{*}{$0006 \pm 0.002$} \\
\hline & & & & $\mathbf{F}$ & $112.9 \pm 10.4^{\mathrm{b}}$ & $0.28 \pm 0.01^{b}$ & $-21.0 \pm 0.8^{\mathrm{a}}$ & \\
\hline & & & \multirow[t]{2}{*}{25} & I & $93.0 \pm 6.2^{\mathrm{a}}$ & $0.24 \pm 0.02^{\mathrm{a}}$ & $-16.1 \pm 0.4^{\mathrm{a}}$ & \multirow[t]{2}{*}{$0.007 \pm 0.001$} \\
\hline & & & & $\mathbf{F}$ & $132.2 \pm 13.4^{\mathrm{b}}$ & $0.32 \pm 0.05^{\mathrm{b}}$ & $-20.2 \pm 1.9^{b}$ & \\
\hline & & \multirow[t]{4}{*}{$50 \%$ ethanol } & 4 & I & $84.3 \pm 4.1^{\mathrm{a}}$ & $0.25 \pm 0.02^{\mathrm{a}}$ & $-21.0 \pm 1.5^{\mathrm{a}}$ & \multirow[t]{2}{*}{$0.006 \pm 0.001$} \\
\hline & & & & $\mathbf{F}$ & $273.8 \pm 4.9^{b}$ & $0.31 \pm 0.03^{b}$ & $-12.5 \pm 0.7^{\mathrm{b}}$ & \\
\hline & & & \multirow[t]{2}{*}{25} & I & $76.0 \pm 1.2^{\mathrm{a}}$ & $0.25 \pm 0.01^{\mathrm{a}}$ & $-18.8 \pm 1.6^{\mathrm{a}}$ & \multirow[t]{2}{*}{$0.010 \pm 0.001$} \\
\hline & & & & $\mathbf{F}$ & $205.5 \pm 26.3^{\mathrm{b}}$ & $0.53 \pm 0.07^{\mathrm{b}}$ & $-10.5 \pm 2.3^{b}$ & \\
\hline \multirow[t]{8}{*}{ Quercetin } & \multirow[t]{8}{*}{ Micro } & \multirow[t]{4}{*}{$10 \%$ ethanol } & \multirow[t]{2}{*}{4} & I & $212.6 \pm 8.9^{\mathrm{a}}$ & $0.25 \pm 0.01^{\mathrm{a}}$ & $-21.1 \pm 1.7^{\mathrm{a}}$ & \multirow[t]{2}{*}{$0.043 \pm 0.006$} \\
\hline & & & & $\mathbf{F}$ & $259.2 \pm 7.8^{\mathrm{b}}$ & $0.23 \pm 0.01^{\mathrm{a}}$ & $-18.2 \pm 2.3^{\mathrm{a}}$ & \\
\hline & & & \multirow[t]{2}{*}{25} & I & $249.3 \pm 3.3^{\mathrm{a}}$ & $0.18 \pm 0.02^{\mathrm{a}}$ & $-19.8 \pm 0.9^{\mathrm{a}}$ & \multirow[t]{2}{*}{$0.003 \pm 0.002$} \\
\hline & & & & $\mathbf{F}$ & $253.5 \pm 4.2^{\mathrm{b}}$ & $0.17 \pm 0.02^{\mathrm{a}}$ & $-23.0 \pm 1.3^{\mathrm{b}}$ & \\
\hline & & \multirow[t]{4}{*}{$50 \%$ ethanol } & \multirow[t]{2}{*}{4} & I & $276.6 \pm 4.1^{\mathrm{a}}$ & $0.20 \pm 0.02^{\mathrm{a}}$ & $-20.7 \pm 1.3^{\mathrm{a}}$ & \multirow[t]{2}{*}{$0.004 \pm 0.001$} \\
\hline & & & & $\mathbf{F}$ & $666.9 \pm 11.8^{\mathrm{b}}$ & $0.20 \pm 0.04^{\mathrm{a}}$ & $-9.5 \pm 0.2^{\mathrm{b}}$ & \\
\hline & & & 25 & I & $245.9 \pm 7.7^{\mathrm{a}}$ & $0.18 \pm 0.01^{\mathrm{a}}$ & $-20.1 \pm 1.3^{\mathrm{a}}$ & $0.002 \pm 0.001$ \\
\hline & & & & F & $556.0 \pm 15.9^{b}$ & $0.18 \pm 0.02^{\mathrm{a}}$ & $-9.5 \pm 0.8^{\mathrm{b}}$ & \\
\hline
\end{tabular}

NOTE: T: Temperature; I: Initial release; F: Final release; ${ }^{\mathrm{a}, \mathrm{b}}$ Small superscript letters within column indicate statistical difference between initial and final means $(p \leq 0.05)$ for the same parameter.

concentration of riboflavin, while $\beta$ - $\mathrm{Lg}$ microstructures were able to maintain ca. $2.5 \%$ of the initial concentration of quercetin, both over $72 \mathrm{~h}$, independently of the food simulant and temperature used.

\section{Conclusions}

$\beta$-Lg micro- and nanostructures were able to bind bioactive compounds with different physicochemical properties (i.e., water solubility). $\beta$-Lg nanostructures maintained their physicochemical properties (i. e., size, PDI and surface charge) independently of the concentrations of both bioactive model compounds added. Furthermore, $\beta$-Lg nanostructures showed a higher association efficiency and loading capacity when compared with $\beta$-Lg microstructures, for the same concentration of hydrophilic (riboflavin) or hydrophobic (quercetin) bioactive compound used. These structures exhibited stability under acidic ( $\mathrm{pH} 2$ to 3 ) and neutral (pH 6 to 10) $\mathrm{pH}$ conditions, at relatively high ionic strength ( $\mathrm{NaCl}$ concentrations up to $100 \mathrm{mmol} \mathrm{L}^{-1}$ ) and thermal processing (until $70{ }^{\circ} \mathrm{C}$ ) conditions. $\beta$ - $\mathrm{Lg} /$ riboflavin micro- and nanostructures showed to be stable over 90 days of storage, while $\beta$ - $\mathrm{Lg}$ /quercetin microstructures were stable during 50 days of storage, being susceptible to aggregation and precipitation after that period. The release for both bioactive model compounds from $\beta$-Lg micro- and nanostructures demonstrated that the LSM model was the most suitable to describe the release kinetics, which is mainly governed by a relaxation mechanism. Additionally, the refrigerated temperature of $4{ }^{\circ} \mathrm{C}$ allowed a slow release of both bioactive model compounds, when compared with the results at room temperature $\left(25^{\circ} \mathrm{C}\right)$, independently of the food simulant used.

Our findings improve the knowledge about the potential applicability of $\beta$-Lg micro- and nanostructures for delivery and controlled release of hydrophilic and hydrophobic bioactive compounds into food systems with different hydrophilic natures. Nevertheless, further investigations regarding the evaluation of bioaccessibility and bioavailability of these bioactive model compounds upon ingestion are needed before their possible application into real food products.

\section{Acknowledgements}

(Conselho Nacional de Desenvolvimento Científico e Tecnológico, Brasil) from Brazil. Oscar L. Ramos gratefully acknowledge the Fundação para a Ciência e a Tecnologia (FCT, Portugal) for his fellowships (SFRH/ BPD/80766/2011). This study was supported by FCT under the scope of the strategic funding of UID/Multi/50016/2019 and UID/BIO/04469/ 2013 units and COMPETE 2020 (POCI-01-0145-FEDER-006684) and BioTecNorte operation (NORTE-01-0145-FEDER-000004) funded by the European Regional Development Fund under the scope of Norte2020 Programa Operacional Regional do Norte. This study was also supported by FCT under the scope of the Project RECI/BBB-EBI/0179/2012 (FCOMP-01-0124-FEDER-027462).

\section{Appendix A. Supplementary data}

Supplementary data to this article can be found online at https://doi. org/10.1016/j.foodhyd.2019.105492.

\section{References}

Aditya, N. P., Macedo, A. S., Doktorovova, S., Souto, E. B., Kim, S., Chang, P. S., et al. (2014). Development and evaluation of lipid nanocarriers for quercetin delivery: A comparative study of solid lipid nanoparticles (SLN), nanostructured lipid carriers (NLC), and lipid nanoemulsions (LNE). Lebensmittel-Wissenschaft und -TechnologieFood Science and Technology, 59(1), 115-121. https://doi.org/10.1016/j. lwt.2014.04.058.

Aprodu, I., Ursache, F. M., Turturica, M., Râpeanu, G., \& Stanciuc, N. (2017). Thermal stability of the complex formed between carotenoids from sea buckthorn (Hippophae rhamnoides L.) and bovine $\beta$-lactoglobulin. Spectrochimica Acta Part A: Molecular and Biomolecular Spectroscopy, 173, 562-571. https://doi.org/10.1016/j. saa.2016.10.010.

Ashoori, M., \& Saedisomeolia, A. (2014). Riboflavin (vitamin B2) and oxidative stress: A review. British Journal of Nutrition, 111(11), 1985-1991. https://doi.org/10.1017/ S0007114514000178.

Azevedo, M. A., Bourbon, A. I., Vicente, A. A., \& Cerqueira, M. A. (2014). Alginate/ chitosan nanoparticles for encapsulation and controlled release of vitamin B2. International Journal of Biological Macromolecules, 71, 141-146. https://doi.org/ 10.1016/j.ijbiomac.2014.05.036.

Bengoechea, C., Peinado, I., \& McClements, D. J. (2011). Formation of protein nanoparticles by controlled heat treatment of lactoferrin: Factors affecting particle characteristics. Food Hydrocolloids, 25(5), 1354-1360. https://doi.org/10.1016/j. foodhyd.2010.12.014. 
Berens, A. R., \& Hopfenberg, H. B. (1978). Diffusion and relaxation in glassy polymer powders: 2. Separation of diffusion and relaxation parameters. Polymer, 19(5), 489-496. https://doi.org/10.1016/0032-3861(78)90269-0.

Berino, R. P., Báez, G. D., Ballerini, G. A., Llopart, E. E., Busti, P. A., Moro, A., et al. (2019). Interaction of vitamin D3 with beta-lactoglobulin at high vitamin/protein ratios: Characterization of size and surface charge of nanoparticles. Food Hydrocolloids, 90, 182-188. https://doi.org/10.1016/j.foodhyd.2018.11.027. October 2018.

Beztsinna, N., Solé, M., Taib, N., \& Bestel, I. (2016). Bioengineered riboflavin in nanotechnology. Biomaterials, 80, 121-133. https://doi.org/10.1016/j. biomaterials.2015.11.050.

Bourbon, A. I., Cerqueira, M. A., \& Vicente, A. A. (2016). Encapsulation and controlled release of bioactive compounds in lactoferrin-glycomacropeptide nanohydrogels: Curcumin and caffeine as model compounds. Journal of Food Engineering, 180, 110-119. https://doi.org/10.1016/j.jfoodeng.2016.02.016.

Bourbon, A. I., Pinheiro, A. C., Carneiro-da-Cunha, M. G., Pereira, R. N., Cerqueira, M.a., \& Vicente, A.a. (2015). Development and characterization of lactoferrin-GMP nanohydrogels: Evaluation of $\mathrm{pH}$, ionic strength and temperature effect. Food Hydrocolloids, 48, 292-300. https://doi.org/10.1016/j.foodhyd.2015.02.026.

Bourbon, A. I., Pinheiro, A. C., Cerqueira, M. A., \& Vicente, A. A. (2016). Influence of chitosan coating on protein-based nanohydrogels properties and in vitro gastric digestibility. Food Hydrocolloids, 60, 109-118. https://doi.org/10.1016/j. foodhyd.2016.03.002.

Cerqueira, M. A., Pinheiro, A. C., Silva, H. D., Ramos, P. E., Azevedo, M. A., FloresLópez, M. L., et al. (2014). Design of bio-nanosystems for oral delivery of functional compounds. Food Engineering Reviews, 6(1-2), 1-19. https://doi.org/10.1007/ s12393-013-9074-3.

Chen, J., Zheng, J., McClements, D. J., \& Xiao, H. (2014). Tangeretin-loaded protein nanoparticles fabricated from zein/\$ $\beta$-lactoglobulin: Preparation, characterization, and functional performance. Food Chemistry, 158, 466-472. https://doi.org/ 10.1016/j.foodchem.2014.03.003.

Collini, M., D'Alfonso, L., \& Baldini, G. (2009). New insight on $\beta$-lactoglobulin binding sites by 1-anilinonaphthalene-8-sulfonate fluorescence decay. Protein Science, 9(10), 1968-1974. https://doi.org/10.1110/ps.9.10.1968.

Commission, E. (2011). Commission recommendation of 18 October 2011 on the definition of nanomaterial (2011/696/EU). Official Journal of the European Union, L275, 38-40. https://doi.org/10.2777/13162. June 2010.

Commission, E. (2011). Regulation (EU) No 10/2011 of the European Parliament and of the Council of 14 January 2011 on on plastic materials and articles intended to come into contact with food. Official Journal of the European Union.

Delahaije, R. J. B. M., Wierenga, P. A., Giuseppin, M. L. F., \& Gruppen, H. (2015). Comparison of heat-induced aggregation of globular proteins. Journal of Agricultural and Food Chemistry, 63(21), 5257-5265. https://doi.org/10.1021/acs.jafc.5b00927.

Devi, N., Sarmah, M., Khatun, B., \& Maji, T. K. (2017). Encapsulation of active ingredients in polysaccharide-protein complex coacervates. Advances in Colloid and Interface Science, 239, 136-145. https://doi.org/10.1016/j.cis.2016.05.009.

Essemine, J., Hasni, I., Carpentier, R., Thomas, T. J., \& Tajmir-Riahi, H. A. (2011). Binding of biogenic and synthetic polyamines to $\beta$-lactoglobulin. International Journal of Biological Macromolecules, 49(2), 201-209. https://doi.org/10.1016/j. ijbiomac.2011.04.016.

Gironés-Vilaplana, A., Villaño, D., Marhuenda, J., Moreno, D. A., \& García-Viguera, C. (2017). Vitamins. In C. Galanakis (Ed.), Nutraceutical and functional food component (pp. 159-201). Elsevier. https://doi.org/10.1016/B978-0-12-805257-0.00006-5. First Edit.

Gomaa, A. I., Nsonzi, F., Sedman, J., \& Ismail, A. A. (2016). Enhanced unfolding of bovine $\beta$-lactoglobulin structure using microwave treatment: A multi-spectroscopic study. Food Biophysics, 11(4), 370-379. https://doi.org/10.1007/s11483-016-9451 6.

Guo, Y., Harris, P., Kaur, A., Pastrana, L., \& Jauregi, P. (2017). Characterisation of $\beta$-lactoglobulin nanoparticles and their binding to caffeine. Food Hydrocolloids, 71, 85-93. https://doi.org/10.1016/j.foodhyd.2017.04.027.

Haghi, A., Azimi, H., \& Rahimi, R. (2017). A comprehensive review on pharmacotherapeutics of three phytochemicals, curcumin, quercetin, and allicin, in the treatment of gastric cancer. Journal of Gastrointestinal Cancer, 48(4), 314-320. https://doi.org/10.1007/s12029-017-9997-7.

Heydari, A., Mehrabi, F., Shamspur, T., Sheibani, H., \& Mostafavi, A. (2018). Encapsulation and controlled release of vitamin B2 using peracetyl- $\beta$-cyclodextrin polymer-based electrospun nanofiber scaffold. Pharmaceutical Chemistry Journal, 52 (1), 19-25. https://doi.org/10.1007/s11094-018-1759-8.

Hu, K., \& McClements, D. J. (2014). Fabrication of surfactant-stabilized zein nanoparticles: A pH modulated antisolvent precipitation method. Food Research International, 64, 329-335. https://doi.org/10.1016/j.foodres.2014.07.004.

Jafari, S. M. (2017). An introduction to nanoencapsulation techniques for the food bioactive ingredients. In Seid Mahdi Jafari (Ed.), Nanoencapsulation of food bioactive Ingredients (pp. 1-47). Academic Press Ltd./Elsevier Science Ltd.

Jafari, S. M., \& McClements, D. J. (2017). Nanotechnology approaches for increasing nutrient bioavailability. InAdvances in food and nutrition research (1st ed., Vol. 81). Elsevier Inc. https://doi.org/10.1016/bs.afnr.2016.12.008.

Kang, Y.-R., Lee, Y.-K., Kim, Y. J., \& Chang, Y. H. (2019). Characterization and storage stability of chlorophylls microencapsulated in different combination of gum Arabic and maltodextrin. Food Chemistry, 272, 337-346. https://doi.org/10.1016/j. foodchem.2018.08.063. March 2018.

Komori, A., Inoue, N., Fujita, K., Kasajima, S.Horii, A., ... (2007). Measurement of rutin and quercetin in tartary buckwheat flour by ultraviolet-induced fluorescence. In Proceedings of the loth. Retrieved from http://citeseerx.ist.psu.edu/viewdoc/downlo ad?doi $=10.1 \cdot 1.578 .2253 \&$ rep $=$ rep1\&type $=$ pdf.
Kumari, A., Yadav, S. K., Pakade, Y. B., Singh, B., \& Yadav, S. C. (2010). Development of biodegradable nanoparticles for delivery of quercetin. Colloids and Surfaces B: Biointerfaces, 80(2), 184-192. https://doi.org/10.1016/j.colsurfb.2010.06.002.

Liang, L., \& Subirade, M. (2012). Study of the acid and thermal stability of $\beta$-lactoglobulin-ligand complexes using fluorescence quenching. Food Chemistry, 132 (4), 2023-2029. https://doi.org/10.1016/j.foodchem.2011.12.043.

Liang, L., Tajmir-Riahi, H. a, \& Subirade, M. (2008). Interaction of b-lactoglobulin with resveratrol and its biological implications. Biomacromolecules, 9(1), 50-56. https:// doi.org/10.1021/bm700728k.

Liu, C., Liu, Z., Sun, X., Zhang, S., Wang, S., Feng, F., et al. (2018). Fabrication and characterization of $\beta$-lactoglobulin-based nanocomplexes composed of chitosan oligosaccharides as vehicles for delivery of astaxanthin. Journal of Agricultural and Food Chemistry, 66(26), 6717-6726. https://doi.org/10.1021/acs.jafc.8b00834. research-article.

Li, H., Wang, D., Liu, C., Zhu, J., Fan, M., Sun, X., et al. (2019). Fabrication of stable zein nanoparticles coated with soluble soybean polysaccharide for encapsulation of quercetin. Food Hydrocolloids, 87(May 2018), 342-351. https://doi.org/10.1016/j. foodhyd.2018.08.002.

Luo, Y., Zhang, B., Whent, M., Yu, L. L., \& Wang, Q. (2011). Preparation and characterization of zein/chitosan complex for encapsulation of alpha-tocopherol, and its in vitro controlled release study. Colloids and Surfaces B: Biointerfaces, 85(2), 145-152. https://doi.org/10.1016/j.colsurfb.2011.02.020.

Madalena, D. A., Ramos, Ó. L., Pereira, R. N., Bourbon, A. I., Pinheiro, A. C. Malcata, F. X., et al. (2016). In vitro digestion and stability assessment of $\beta$-lactoglobulin/riboflavin nanostructures. Food Hydrocolloids, 58, 89-97. https:// doi.org/10.1016/j.foodhyd.2016.02.015.

Mansour, A., Abdel-Fattah, A. A., \& Soliman, Y. S. (2014). Gamma radiation-induced effects on riboflavin EPR investigation and spectroscopic analyses. Journal of Drug Delivery Science and Technology, 24(1), 105-110. https://doi.org/10.1016/S17732247(14)50015-9.

Ma, A., Qu, H., Liu, C., Yan, L., Wang, H., Wang, R., et al. (2018). Formulation and characterization of chitosan hydrochloride and carboxymethyl chitosan encapsulated quercetin nanoparticles for controlled applications in foods system and simulated gastrointestinal condition. Food Hydrocolloids, 84, 450-457. https://doi org/10.1016/j.foodhyd.2018.06.025. November 2017.

Martins, J. T., Santos, S. F., Bourbon, A. I., Pinheiro, A. C., González-Fernández, Á., Pastrana, L. M., et al. (2016). Lactoferrin-based nanoparticles as a vehicle for iron in food applications - Development and release profile. Food Research International, 90, 16-24. https://doi.org/10.1016/j.foodres.2016.10.027.

Mcclements, D. J. (2017). The future of food colloids: Next-generation nanoparticle delivery systems. Current Opinion in Colloid \& Interface Science, 28, 7-14. https://doi. org/10.1016/j.cocis.2016.12.002.

McClements, D. J., \& Li, Y. (2010). Review of in vitro digestion models for rapid screening of emulsion-based systems. Food \& Function, 1(1), 32-59. https://doi.org/10.1039/ c0fo00111b.

Mirpoor, S. F., Hosseini, S. M. H., \& Nekoei, A.-R. (2017). Efficient delivery of quercetin after binding to beta-lactoglobulin followed by formation soft-condensed core-shell nanostructures. Food Chemistry, 233, 282-289. https://doi.org/10.1016/j. foodchem.2017.04.126

Monteiro, A. A., Monteiro, M. R., Pereira, R. N., Diniz, R., Costa, A. R., Malcata, F. X., et al. (2016). Design of bio-based supramolecular structures through self-assembly of $\alpha$-lactalbumin and lysozyme. Food Hydrocolloids, 58, 60-74. https://doi.org/ 10.1016/j.foodhyd.2016.02.009.

Morrison, P. W. J., Connon, C. J., \& Khutoryanskiy, V. V. (2013). Cyclodextrin-mediated enhancement of riboflavin solubility and corneal permeability. Molecular Pharmaceutics, 10(2), 756-762. https://doi.org/10.1021/mp3005963.

Musyanovych, A., \& Landfester, K. (2014). Polymer micro- and nanocapsules as biological carriers with multifunctional properties. Macromolecular Bioscience, 14(4), 458-477. https://doi.org/10.1002/mabi.201300551.

Ni, S., Hu, C., Sun, R., Zhao, G., \& Xia, Q. (2017). Nanoemulsions-based delivery systems for encapsulation of quercetin: Preparation, characterization, and cytotoxicity studies. Journal of Food Process Engineering, 40(2), e12374. https://doi.org/10.1111/ jfpe.12374.

Orsuwan, A., Kwon, S., Bumbudsanpharoke, N., \& Ko, S. (2019). Novel LDPE-riboflavin composite film with dual function of broad-spectrum light barrier and antimicrobial activity. Food Control, 100, 176-182. https://doi.org/10.1016/j. foodcont.2019.01.012. January.

O'Neill, G. J., Jacquier, J. C., Mukhopadhya, A., Egan, T., O'Sullivan, M., Sweeney, T., et al. (2015). In vitro and in vivo evaluation of whey protein hydrogels for oral delivery of riboflavin. Journal of Functional Foods, 19, 512-521. https://doi.org/ 10.1016/j.jff.2015.09.043.

Pace, C. N., Treviño, S., Prabhakaran, E., Scholtz, J. M., Franks, F., Wilson, K., et al. (2004). Protein structure, stability and solubility in water and other solvents. Philosophical Transactions of the Royal Society B: Biological Sciences, 359(1448), 1225-1235. https://doi.org/10.1098/rstb.2004.1500.

Patel, A. R., Heussen, P. C. M., Hazekamp, J., Drost, E., \& Velikov, K. P. (2012). Quercetin loaded biopolymeric colloidal particles prepared by simultaneous precipitation of quercetin with hydrophobic protein in aqueous medium. In Food chemistry (Vol. 133, pp. 423-429). Elsevier Ltd. https://doi.org/10.1016/j.foodchem.2012.01.054.

Pinheiro, A. C., Bourbon, A. I., Cerqueira, M. A., Maricato, É., Nunes, C., Coimbra, M. A., et al. (2015). Chitosan/fucoidan multilayer nanocapsules as a vehicle for controlled release of bioactive compounds. Carbohydrate Polymers, 115, 1-9. https://doi.org/ 10.1016/j.carbpol.2014.07.016.

Pinheiro, A. C., Bourbon, A. I., Quintas, M. A. C., Coimbra, M. A., \& Vicente, A. A. (2012). K-Carrageenan/Chitosan nanolayered coating for controlled release of a model 
bioactive compound. Innovative Food Science \& Emerging Technologies, 16, 227-232. https://doi.org/10.1016/j.ifset.2012.06.004.

Pinheiro, A. C., Gonçalves, R. F. S., Madalena, D. A., \& Vicente, A. A. (2017). Towards the understanding of the behavior of bio-based nanostructures during in vitro digestion. Current Opinion in Food Science. https://doi.org/10.1016/j.cofs.2017.06.005.

Ramos, O. L., Pereira, R. N., Martins, A., Rodrigues, R., Fuciños, C., Teixeira, J.a., et al. (2017). Design of whey protein nanostructures for incorporation and release of nutraceutical compounds in food. Critical Reviews in Food Science and Nutrition, 57(7), 1377-1393. https://doi.org/10.1080/10408398.2014.993749.

Ramos, O. L., Pereira, R. N., Rodrigues, R., Teixeira, J. A., Vicente, A. A., \& Xavier Malcata, F. (2014). Physical effects upon whey protein aggregation for nano-coating production. Food Research International, 66, 344-355. https://doi.org/10.1016/j. foodres.2014.09.036.

Ramos, O. L., Pereira, J. O., Silva, S. I., Amorim, M. M., Fernandes, J. C., Lopes-daSilva, J. A., et al. (2012). Effect of composition of commercial whey protein preparations upon gelation at various $\mathrm{pH}$ values. Food Research International, 48(2), 681-689. https://doi.org/10.1016/j.foodres.2012.06.004.

Ramos, Ó. L., Reinas, I., Silva, S. I., Fernandes, J. C., Cerqueira, M. A., Pereira, R. N., et al. (2013). Effect of whey protein purity and glycerol content upon physical properties of edible films manufactured therefrom. Food Hydrocolloids, 30(1), 110-122. https:// doi.org/10.1016/j.foodhyd.2012.05.001.

Sedaghat Doost, A., Muhammad, D. R. A., Stevens, C. V., Dewettinck, K., \& Van der Meeren, P. (2018). Fabrication and characterization of quercetin loaded almond gum-shellac nanoparticles prepared by antisolvent precipitation. Food Hydrocolloids, 83, 190-201. https://doi.org/10.1016/j.foodhyd.2018.04.050.

Shafaei, Z., Ghalandari, B., Vaseghi, A., Divsalar, A., Haertlé, T., Saboury, A. A., et al. (2017). $\beta$-Lactoglobulin: An efficient nanocarrier for advanced delivery systems. Nanomedicine: Nanotechnology, Biology and Medicine, 13(5), 1685-1692. https://doi. org/10.1016/j.nano.2017.03.007.

Shpigelman, A., Cohen, Y., \& Livney, Y. D. (2012). Thermally-induced $\beta$-lactoglobulinEGCG nanovehicles: Loading, stability, sensory and digestive-release study. Food Hydrocolloids, 29(1), 57-67. https://doi.org/10.1016/j.foodhyd.2012.01.016.

Simões, L. S., Araújo, J. F., Vicente, A. A., \& Ramos, O. L. (2020). Design of $\beta$-lactoglobulin micro- and nanostructures by controlling gelation through physical variables. Food Hydrocolloids, 100, 105357. https://doi.org/10.1016/j. foodhyd.2019.105357. February 2019.

Simões, L. S., Madalena, D. A., Pinheiro, A. C., Teixeira, J. A., Vicente, A. A., \& Ramos, Ó. L. (2017). Micro- and nano bio-based delivery systems for food applications: In vitro behavior. Advances in Colloid and Interface Science, 243, 23-45 https://doi.org/10.1016/j.cis.2017.02.010.

Singh, H. (2016). Nanotechnology applications in functional Foods; opportunities and challenges. Preventive Nutrition and Food Science, 21, 1-8. https://doi.org/10.3746/ pnf.2016.21.1.1. February.

Singh, K., Hussain, I., Mishra, V., \& Akhtar, M. S. (2019). New insight on 8-anilino-1naphthalene sulfonic acid interaction with TgFNR for hydrophobic exposure analysis. International Journal of Biological Macromolecules, 122, 636-643. https:// doi.org/10.1016/j.ijbiomac.2018.10.208.

Tokle, T., Mao, Y., \& McClements, D. J. (2013). Potential biological fate of emulsionbased delivery systems: Lipid particles nanolaminated with lactoferrin and $\beta$-lactoglobulin coatings. Pharmaceutical Research, 30(12), 3200-3213. https://doi. org/10.1007/s11095-013-1003-x.
Wang, Q., Ren, Y., Ding, Y., Xu, M., \& Chen, B. (2018). The influence of pH and enzyme cross-linking on protein delivery properties of WPI-beet pectin complexes. Food Research International, 105, 678-685. https://doi.org/10.1016/j. foodres.2017.11.076.

Wang, W., Zhong, Q., \& Hu, Z. (2013). Nanoscale understanding of thermal aggregation of whey protein pretreated by transglutaminase. Journal of Agricultural and Food Chemistry, 61(2), 435-446. https://doi.org/10.1021/jf304506n.

Wichchukit, S., Oztop, M. H., McCarthy, M. J., \& McCarthy, K. L. (2013). Whey protein/ alginate beads as carriers of a bioactive component. Food Hydrocolloids, 33(1), 66-73. https://doi.org/10.1016/j.foodhyd.2013.02.013.

Wijaya, W., Harfieyanto, R. C., Dewettinck, K., Patel, A. R., \& Van der Meeren, P. (2019). Whey protein isolate-low methoxyl pectin nanocomplexes improve physicochemical and stability properties of quercetin in a model fat-free beverage. Food \& Function, 1-11. https://doi.org/10.1039/c8fo02350f.

Xu, H., Lu, Y., Zhang, T., Liu, K., Liu, L., He, Z., et al. (2019). Characterization of binding interactions of anthraquinones and bovine $\beta$-lactoglobulin. Food Chemistry, 281, 28-35. https://doi.org/10.1016/j.foodchem.2018.12.077, 2018.

Yan, L., Wang, R., Wang, H., Sheng, K., Liu, C., Qu, H., et al. (2018). Formulation and characterization of chitosan hydrochloride and carboxymethyl chitosan encapsulated quercetin nanoparticles for controlled applications in foods system and simulated gastrointestinal condition. Food Hydrocolloids, 84, 450-457. https://doi. org/10.1016/j.foodhyd.2018.06.025. November 2017.

Ye, Q., Woo, M. W., \& Selomulya, C. (2019). Modification of molecular conformation of spray-dried whey protein microparticles improving digestibility and release characteristics. Food Chemistry, 280, 255-261. https://doi.org/10.1016/j. foodchem.2018.12.074. December 2018.

Yi, J., Fan, Y., Zhang, Y., Wen, Z., Zhao, L., \& Lu, Y. (2016). Glycosylated $\alpha$-lactalbuminbased nanocomplex for curcumin: Physicochemical stability and DPPH-scavenging activity. Food Hydrocolloids, 61, 369-377. https://doi.org/10.1016/j. foodhyd.2016.05.036.

Yoshizawa, S., Arakawa, T., \& Shiraki, K. (2014). Dependence of ethanol effects on protein charges. International Journal of Biological Macromolecules, 68, 169-172. https://doi.org/10.1016/j.ijbiomac.2014.04.041.

Zagury, Y., Kazir, M., \& Livney, Y. D. (2019). Improved antioxidant activity, bioaccessibility and bioavailability of EGCG by delivery in $\beta$-lactoglobulin particles. Journal of Functional Foods, 52, 121-130. https://doi.org/10.1016/j.jff.2018.10.025. October 2018.

Zhang, J., Teng, Z., Yuan, Y., Zeng, Q. Z., Lou, Z., Lee, S. H., et al. (2018). Development, physicochemical characterization and cytotoxicity of selenium nanoparticles stabilized by beta-lactoglobulin. International Journal of Biological Macromolecules, 107, 1406-1413. https://doi.org/10.1016/j.ijbiomac.2017.09.117.

Zhang, P., Zhao, S. R., Li, J. X., Hong, L., Raja, M. A., Yu, L. J., et al. (2016). Nanoparticles based on phenylalanine ethyl ester-alginate conjugate as Vitamin B2 delivery system. Journal of Biomaterials Applications, 31(1), 13-22. https://doi.org/ 10.1177/0885328216630497.

Zou, L., Zheng, B., Zhang, R., Zhang, Z., Liu, W., Liu, C., et al. (2016). Food-grade nanoparticles for encapsulation, protection and delivery of curcumin: Comparison of lipid, protein, and phospholipid nanoparticles under simulated gastrointestinal conditions. RSC Advances, 6(4), 3126-3136. https://doi.org/10.1039/C5RA22834D. 